\title{
Strain variation analysis of cross-laminated timber elements under cyclic moisture
}

\author{
Catarina Silva $^{\mathrm{a}}$, Jorge M. Branco ${ }^{\mathrm{a}, *}$, Zabih Mehdipour ${ }^{\mathrm{a}}$, José Xavier ${ }^{\mathrm{b}}$, Arthur S. Rebouças ${ }^{\mathrm{c}}$, \\ Paulo B. Lourenço ${ }^{a}$ \\ ${ }^{\text {a }}$ ISISE, University of Minho, Portugal \\ ${ }^{\mathrm{b}}$ Nova School of Science and Technology, University NOVA Lisbon, Portugal \\ ${ }^{\mathrm{c}}$ Federal Institute of Education, Science and Technology of Rio Grande do Norte, Brazil
}

\section{A R T I C L E I N F O}

\section{Keywords:}

Cross laminated timber

Moisture content

Relative humidity

Digital image correlation

\begin{abstract}
A B S T R A C T
Despite the growing use of cross-laminated timber (CLT) panels in the construction industry, their behaviours under weather conditions, especially cyclic moisture which generated additional strains, requires further investigation. To address this gap, an extensive experimental campaign was carried out to evaluate CLT elements, in which strains are measured, under cyclic moisture changes, using Digital Image Correlation (DIC). In this way, the effects of cyclic humidity changes on amplitude and distribution of strains on four different configurations of CLT panels, divided based on the free flow direction of moisture, are explained. Regarding RH cycle tests, CLT specimens were conditioned in climatic chambers for 324 days at constant temperature $20\left({ }^{\circ} \mathrm{C}\right)$ with a humidity cycle varying every 21 days between $30 \%$ and $90 \%$, getting constant at $65 \%$ after the first 142 days. Results show that, in the main face, drying periods present tensile strain while wetting periods present compressive strains in the longitudinal direction. But, in the tangential direction, restrained strains tend to reduce significantly from first to last drying cycles for all test configurations. Moreover, in the lateral face, drying periods present tensile strains while wetting periods present compressive strains in the tangential direction. Experimental results confirmed that the ratio between tangential and longitudinal directions tends to decrease with the number of RH cycles, and successive RH cycles do not cause cumulative strains on CLT panels.
\end{abstract}

\section{Introduction}

Wood is a biological material that interacts with its surrounding environment. It can shrink and swell depending the air temperature and relative humidity (RH). This hygroscopic behaviour varies among wood species. This behaviour is naturally transferred to wood-based products. However, the rate can vary between solid wood and timber engineering materials built from the same wood species. One example is crosslaminated timber (CLT), which with its cross-wise lamination, restrict moisture-induced movements obtaining reduced rates of shrinkage/ swelling in-plane directions when compared with solid wood of the same species, whereas discontinuities in the layup CLT affect the hygroscopic behaviour of the product [1]. Tripathi et al. [2] showed that cross-laminated timber (CLT) panels made of Eastern red spruce (Picea rubens) have a higher hygroscopic rate than that of laminated strand lumber (LSL). Schwab et al. [3] studied the in-plane dimensional variation of three-layered cross-laminated panels from Norway spruce (Picea abies) with a thickness of $20 \mathrm{~mm}$ and calculated its swelling coefficients $\alpha x^{1}:=0.012 \ldots 0.020 \%$ and $\alpha y^{2}=0.034 \ldots 0.042 \%$ (percentage change in length per $1 \%$ change in moisture content). Brandner [4] indicates that the swelling and shrinkage rates of CLT panels of Norway spruce (Picea abies), with moisture content (MC), kept between $6 \%$ and $22 \%$, are $0.02 \%$ per each percentage unit of MC added for both directions in the plane. Bengtsson [5] performed tests on solid timber of the same species with MC kept between $8 \%$ and $20 \%$, and obtained range values $0.001 \ldots 0.035 \%$ and $0.18 \ldots 0.46 \%$ for longitudinal and tangential directions, respectively. Kukk et al. [6] with the aim of determining the maximum allowable initial MC for CLT walls, having both exterior and interior thermal insulation, concluded that the allowable MC ranges between $8 \%$ and $16 \%$ for construction timber. In

\footnotetext{
* Corresponding author.

E-mail addresses: jbranco@civil.uminho.pt, jotabranco@gmail.com (J.M. Branco).

1 grain direction of outer layers.

2 grain direction of middle layer.
} 


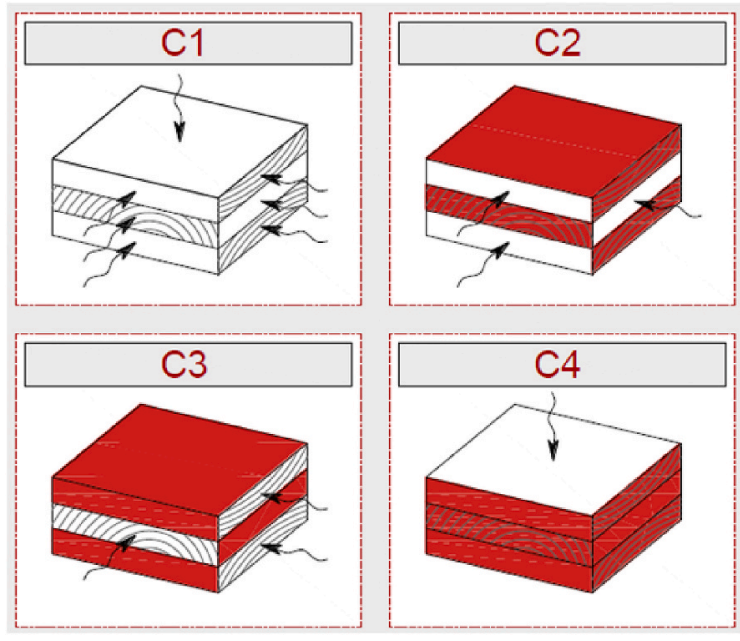

Fig. 1. Different specimen configurations and respective dimensions and directions for measurements.

C1 - Three directions allow free moisture flow; C2

- Only tangential direction allow free moisture flow; C3 - Only longitudinal direction allows free moisture flow; C4 - Only radial direction allow free moisture flow.

the same trend [7], show the importance of the hygroscopic behaviour of CLT elements during the construction process.

Besides the changes in geometry, moisture variations can also lead to changes in wood mechanical properties, such as shear strength and modulus and, consequently, changes in the load-carrying capacity of the timber elements [1]. According to Hoffmeyer [8], the modulus of elasticity (MOE) in grain direction of defect-free timber drops by approximately $1.5 \%$ if the wood moisture is increased by $1 \%$.Gülzow et al. [9] conducted a study to understand the impact of moisture content changes on stiffness parameters of CLT panels. For that propose, bending and shear moduli were measured on all directions considering different moisture contents, namely $12 \pm 2 \%, 18.5 \pm 1.4 \%$, and $10.6 \pm 1.4 \%$. The results obtained showed that all investigated stiffness parameters decrease at they mean level towards an increase of MC. However, the authors emphasized that swelling of the timber grain leads to an apparent increase in the modulus of elasticity for small service loads due to internal component friction. On the other hand, cracking resulted from the reduction of moisture content leads directly to a distinct decrease in the bending stiffness perpendicular to the grain direction on the face layers.

Moisture gradients increase internal stresses of woods and induce significant differences in shrinkage and swelling of wood, which will develop so-called moisture induced-stresses (MIS), leading to cracks either in timber surface or in its central part of timber sections. Nairn [10] derived an expression for energy released when these cracks form within a layer, predicting layer cracking under many conditions such as cracking due to residual shrinkage alone and cracking due to uniaxial tension. This attempt concluded in proposing two simple changes to CLT that could greatly enhance durability, which is to use thinner layers and to dry the timber before panel fabrication sufficiently. It has been proven by measurements and experimental work that MIS can exceed the tensile strength of timbers, particularly in the case of glulam cross-sections, perpendicular to the grain $[9,10]$. Due to unequal distribution of moisture content within the hygroscopic range, residual stresses will develop between adjacent layers as each layer independently shrinks or expands, causing excessive cracking of CLT panels as a result of significantly weakening the bond strength [7].

Studies focused on the effects of moisture-induced stresses (MIS) on CLT are scarce. Some work in this field was developed by Gereke [11], who measured linear swelling in three directions of a CLT panel, between relative humidity of $35 \%$ and $85 \%$. Considering the same $\mathrm{RH}$ range, Gereke [11] also realized comparative measurements of internal stresses of CLT specimens with three layers, in which the material of the middle layer varies. The measurements were made manually by means of a linear gauge, which can lead to significant inaccuracy. The author concluded that the free swelling and shrinkage of adjacent layers differ by a factor of 10 (radial/longitudinal) to 20 (tangential/longitudinal), resulting in serious structural damages and shape distortions, which may reduce the material serviceability. Often MIS exceeds the tensile strength of timber perpendicular to the grain, leading to cracks (either on the surface of timber or in the central part of timber sections), shape distortions and reduction of load-bearing capacity (by splitting failure). More recently, Hassani et al. [12] conducted a combined experimental and numerical study to characterize inter- and intra-laminar damage evolution in cross-laminated samples from European beech due to climatic changes. It was proven that the moisture-induced damage in beech lamellae can be addressed using a modified analytical micro-mechanics of damage model, originally developed for cross-ply laminates.

Despite the value of past researches and, in particular, the important outcomes reached by Gereke [11] and Hassani et al. [12], the effect of moisture variation on the CLT strain and stresses is not well understood for the moment. Due to the stress-strain relation, the authors believe that it is fundamental to start with the analysis on the strain variation that CLT elements presents under moisture variation. In this context, the present work aims to contribute to fulfill this gap of knowledge on the moisture-induced strains on CLT, presenting an experimental work performed with three-layered CLT panels aimed to measure strains induced by cyclic moisture changes using Digital Image Correlation (DIC) technique.

\section{Experimental campaign}

\subsection{Preparation of the CLT specimens}

The preparation of the CLT specimens used in the experimental campaign followed six main steps: i) production of the CLT; ii) specimens were cut with defined dimensions; iii) timber directions were sealed; iv) specimens were painted with a random pattern; v) specimens were photographed; and vi) specimens were conditioned in a climatic chamber under controlled conditions.

The production of the CLT was carried out at Rusticasa, an industry in the North of Portugal. It is important to note that this industry has no experience in the CLT production, and therefore, it was necessary to adapt the production process to the equipment and facilities of the factory. All the elementary rules of the production of glued-timber elements were followed but, for example, it was impossible to control the density distribution of the boards used in the CLT production. CLT was produced in the shape of three big layered beams $(4200 \times 170 \times 102$ $\mathrm{mm}^{3}$ ), laminated with adhesive 1247 from AkzoNobel and pressed by a hydraulic pressing device with a pressure of $1 \mathrm{~N} / \mathrm{mm}^{2}$ for $2.5 \mathrm{~h}$. The timber used for the CLT production was Norway spruce (Picea abies) of strength class C24, with a density range between $410 \mathrm{~kg} / \mathrm{m}^{3}$ and $513 \mathrm{~kg}$ / $\mathrm{m}^{3}\left(\mathrm{CoV}=0.05\right.$ and mean $\left.=460 \mathrm{~kg} / \mathrm{m}^{3}\right)$ and a moisture range between $16.5 \%$ and $20.2 \%(\mathrm{CoV}=0.08$ and mean $=18.4 \%)$. Despite the high moisture content at production time, specimens were subsequently conditioned until a moisture content of around $14 \%$ was reached.

Once stabilized, specimens with configurations C2, C3 and C4 were carefully sealed by means of an elastic membrane Dakorub by Soudal ${ }^{\text {, }}$ in such a way that only one direction allows the free flow of moisture (see Fig. 1). The next step was to prepare the specimens surfaces in which the DIC technique would be applied. So, these surfaces were painted with a speckled pattern by means of black and white aerosol painting. This painting was carefully made in order to obtain a random pattern of black dots on a white background. This way, the camera obtains high-quality image information [13,14]. 


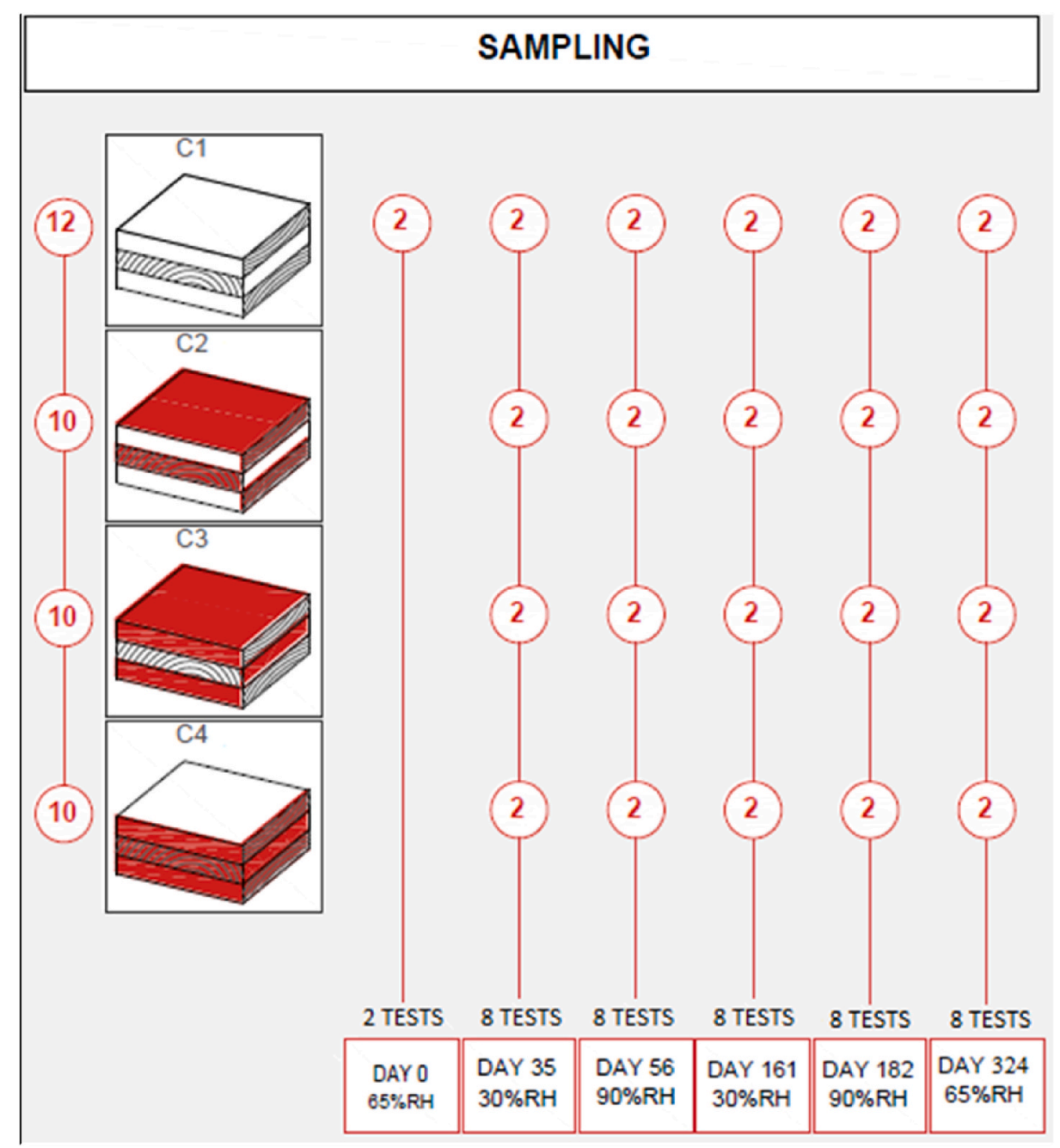

Fig. 2. Overview of the test campaign.

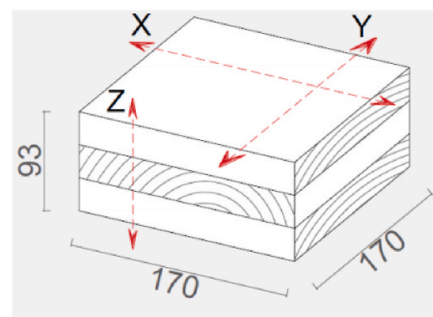

Fig. 3. Different directions defined for the CLT specimens and adopted dimensions (in $\mathrm{mm}$ ).

Per each configuration, 10 specimens were prepared for the test days 35, 56, 161, 182 and 324. Configuration C1 was an exception, being prepared 12 specimens. These two extra specimens were used to measure released strains at day 0 in order to quantify the effect of high moisture content at production time. Fig. 2 summarizes the entire experimental campaign and shows that, at each test moment, two similar specimens were tested.

\subsection{Variables and techniques}

The main goal of the present experimental campaign was the measurement of strains induced in CLT panels by cyclic moisture changes. Strains were measured both in the surface of the main face of CLT panels and in the lateral face of panels. The measurements performed in the main face of panels registered the timber movements for longitudinal $(\mathrm{X})$ and tangential $(\mathrm{Y})$ directions separately, while the measurements performed in the lateral face of panels registered the timber movements on the radial direction ( $\mathrm{Z}$ ) (see Fig. 3). Additionally, measurements made in the lateral face of panels registered the movements of timber on the radial (Z) and tangential (Y) directions, considering the behaviour of different layers separately.

Measurements of timber movements were performed by means of Digital Image Correlation (DIC) technique. DIC technique is an optical, contact-free and full-field measurement technique $[15,16]$. It can be valuable to understand better the effects of cyclic humidity changes on amplitude and distribution of strains on CLT surfaces. The acquisition of images was performed at different moments in order to register the movements on material surface during the defined periods.

This experimental campaign was performed considering two distinct parameters: the RH cycle (test I) and the direction of free moisture flow (test II). Regarding test I, the effect of extreme environmental conditions was evaluated, concerning relative humidity $(\mathrm{RH})$ changes, by means of compressive and tensile strains observed at CLT specimens. Besides, the effects of repeated $\mathrm{RH}$ cyclic changes on measured strains were also verified. So, damages caused in CLT and possible modifications on timber fibers in the course of the conditioning period, were analyzed.

Concerning test II, the goal was to understand the relation between the direction of moisture flow and the strains obtained. This relation was important to study because, considering cross-wise lamination of CLT, 

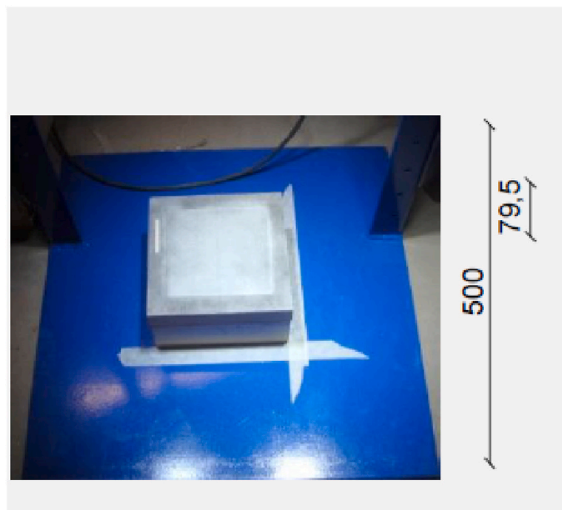

$\stackrel{500}{50, \quad 400 \quad, 50}$

Perforate

L-sectiol

column:

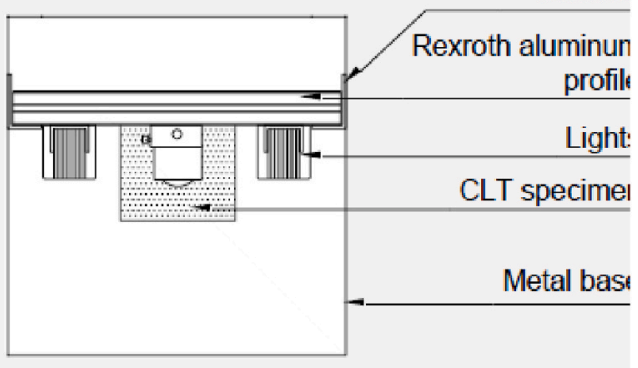

Top view
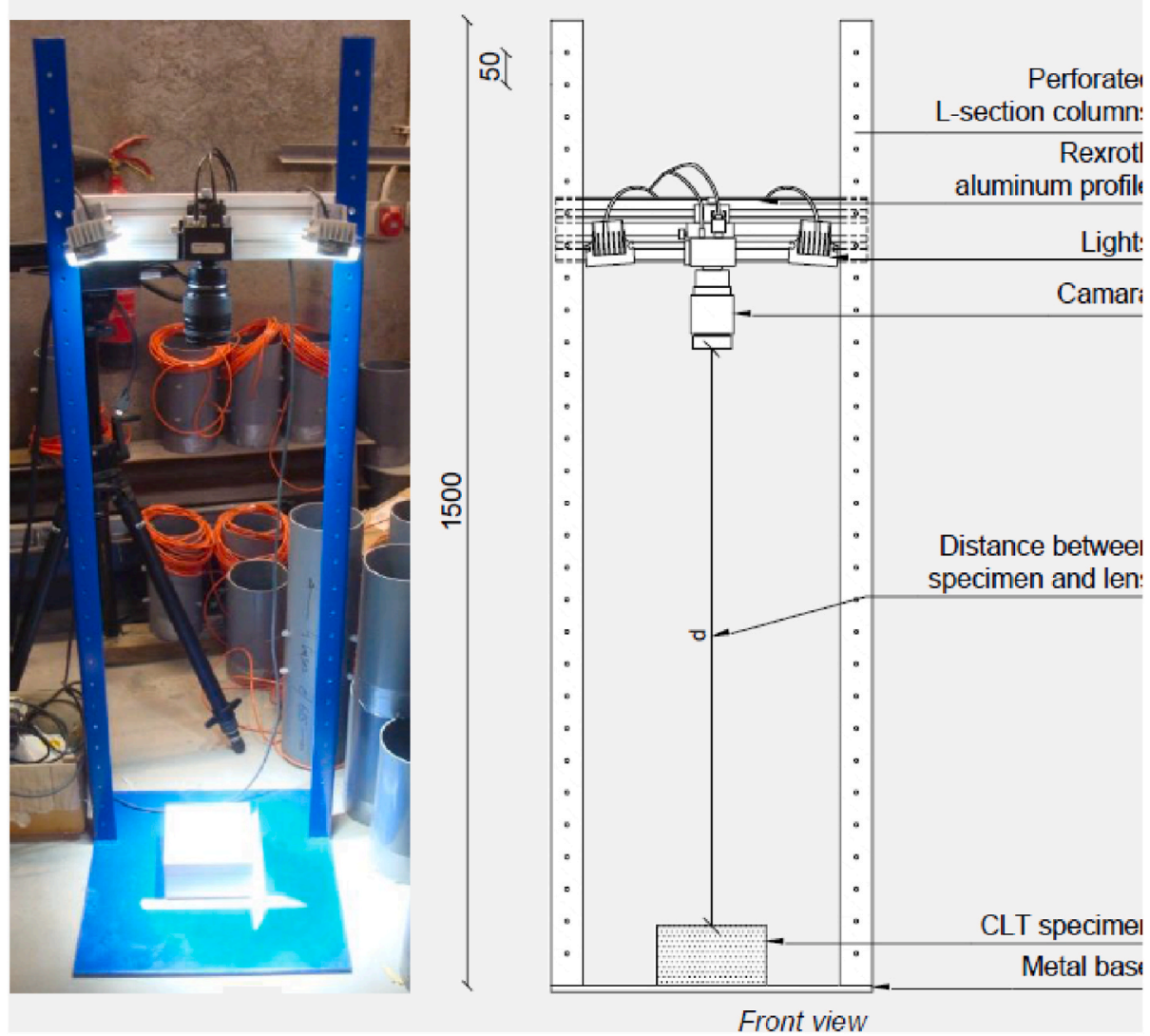

Fig. 4. Test layout: at the left side pictures of steel structure during the test and the right side: drawing of the same steel structure (dimensions in mm).

the restriction of moisture flow in specific directions could result in a different behaviour towards its hygroscopic behaviour compared with CLT panels with free moisture flow.

Test configurations were designed considering both parameters described below. This way, specimens were defined considering different geometries: composed of small CLT panels with dimensions of $170 \times 170 \times 93 \cdot \mathrm{mm}^{3}$ (Fig. 3). Specimens were used to obtain restrained strains $\left(\varepsilon_{\text {rest }}\right)$ on three different directions X, Y (F1) and Z (F2 and F3) and released strains $\left(\varepsilon_{\text {rel }}\right)$ on Y direction of panel surface $(\mathrm{F} 1)$. The faces are clearly shown below. Specimens are composed of 4 different configurations, 1: (C1) allows free-moisture flow through all three timber directions; 2: (C2) allows moisture flow only in tangential direction; 3: (C3) allows moisture flow only in the longitudinal direction, and 4: (C4) allows moisture flow only in the radial direction.

\subsection{Digital Image Correlation (DIC)}

The test setup used for the measurements performed with DIC was one of the main concerns of this experimental campaign. As required by the technique, it was mandatory to ensure that the object is planar, parallel to the camera and keeps a constant distance from the optical system among all tests over time. However, as the camera and specimen had to be replaced at test setup every time measurements were required according to the MC protocol, a reference structure was built to guarantee the alignments among images recorded over time. Fig. 4 depicts the steel structure that was designed for this purpose. It is composed of a steel base and two perforated L-section steel columns in which a horizontal Rexroth aluminum profile can be fixed at the most favorable height. It is in the Rexroth profile that camera and lights were fixed every test, guaranteeing similar setups among measurements.

Despite the care to keep the camera always in the same position, the zoom position was recorded in order to reconstruct the test setup with the same reference. Once these two positions (camera and zoom) were fixed, replacing specimens was guaranteed by the axis drawn in the specimen surface, which should overlap the camera axis (as in the previous section). Furthermore, the conversion factor between pixels and 
Table 1

Components of the optical system and measurement parameters.

\begin{tabular}{ll}
\hline CCD camera & \\
\hline Model & $\begin{array}{l}\text { Baumer Optronic FWX20 } \\
(8 \mathrm{bits}, 1624 \times 1236 \text { pixels, } 4.4 \mu \mathrm{m} / \text { pixel) }\end{array}$ \\
Shutter time & $5 \mathrm{~ms}$ \\
Acquisition frequency & $1 \mathrm{~Hz}$ \\
Lens & Nikon AF Micro-Nikkor \\
Model & $200 \mathrm{~mm} \mathrm{f} / 4 \mathrm{D}$ \\
& $\mathrm{f} / 11$ \\
Aperture & \\
Lighting & \\
LEDMHL10 (color temperature: $6000 \mathrm{~K})$ & \\
Working distance & $966 \mathrm{~mm}$ \\
F1 & $884 \mathrm{~mm}$ \\
F2 and F3 & \\
Conversion factor & $0.127 \mathrm{~mm} / \mathrm{pixel}$ \\
F1 & $0.096 \mathrm{~mm} /$ pixel \\
F2 and F3 & $15 \times 15$ pixel \\
Project parameter - facet & $13 \times 13$ pixel \\
Facet size & \\
Step size & $5 \times 5 \mathrm{subsects}$ \\
Project parameter - Strain & $55 \%$ \\
Computation size & Total \\
Validity code & $1 \mathrm{~Hz}$ \\
Strain compotation method & \\
Image recording & \\
Acquisition frequency & \\
\hline
\end{tabular}

millimeters was done for each tested specimen individually using a reference graph paper $\left(5 \times 50 \mathrm{~mm}^{2}\right)$ glued at surface of specimens.

Image acquisition was performed by an 8-bit Charged-Coupled Device (CCD) Baumer Optronic FWX20 digital camera equipped with a Nikon AF Micro-Nikkor $200 \mathrm{~mm}$ f/4D lens, using the GOM ARAMIS ${ }^{\circledR}$ DIC-2D v6.02 software, as Table 1. Camera and specimen were positioned in the test setup with a distance between them that varies dependent on geometry of specimens, leading to different conversion factors.

According to Table 1, lens aperture was fixed to $\mathrm{f} / 11$, improving the depth of field and shutter time was set to $5 \mathrm{~ms}$. Two lighting sources (LEDMHL10) were used to guarantee the adequate lighting of the specimen surface.

The region of interest (ROI) was defined across the reference image and DIC setting parameters adjusted in a compromise between spatial resolution and accuracy. To subset size of $15 \times 15$ pixels $^{2}$ was selected taking into account the quality of speckled pattern (average of speckle size), over which a correlation domain could be defined with suitable contrast and isotropy. The facet step was set to $13 \times 13$ pixels $^{2}$, with $13 \%$ of pixel overlapping between subsets. Then, the in-plane displacements were computed, and the full-field strain distribution determined, assuming a strain window of $5 \times 5$ subsets. On the one hand, the displacement accuracy was estimated in the range of 0.01-0.02 pixels. On the other hand, the strain resolution was found in between 0.01 and $0.03 \%$. These resolutions were estimated on a statistical basis by considering the standard deviation of the noisy maps obtained carrying out an in-plane translation (rigid-body) movement between the camera and the object $[14,16]$.

DIC was used to compare the behaviour of different configurations designed to understand the effect of moisture flow on CLT hygroscopic behaviour. This choice was essentially based on two main advantages. Firstly, DIC offers full-field deformation measurements. Secondly, the technique requires a simple testing apparatus making it possible to test a large number of specimens with no direct contact.

As mentioned before, all test specimens were imaged before being submitted to the RH cycles (day 0). Theseset of images were then used as the reference state of the specimens. Images were then recorded sequentially again for the remaining test days (day 35, day 56, day 161 , day 182 and day 324). Similarly to some published works (Angst \& Malo [17], Gereke [11] and Jönsson [18]), two different DIC maps were done at each test day. Firstly, DIC maps were done considering the effect of humidity loads on the unchanged specimens, measuring restrained strains $\left(\varepsilon_{\text {rest }}\right)$. Secondly, DIC maps were done considering the effect of humidity loads on the sliced specimens, measuring released strains $\left(\varepsilon_{\text {rel }}\right)$ caused by cross lamination through the panel surface (Fig. 5). Restrained and released strains were calculated as given in the following equations:

$\varepsilon_{\text {rest }}=\left(L_{1}-L_{0}\right) / L_{0}$

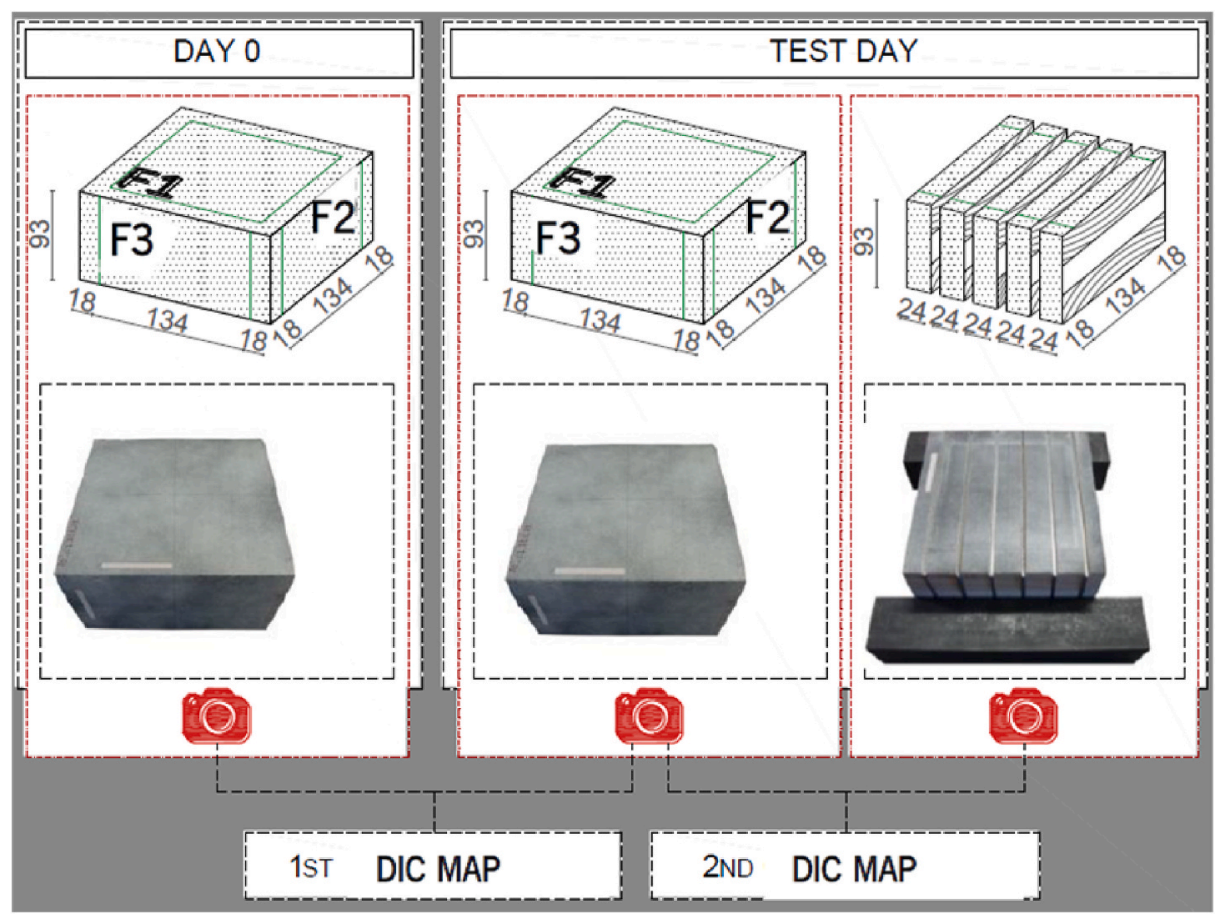

Fig. 5. Measurements made on different test days (dimensions in $\mathrm{mm}$ ). 


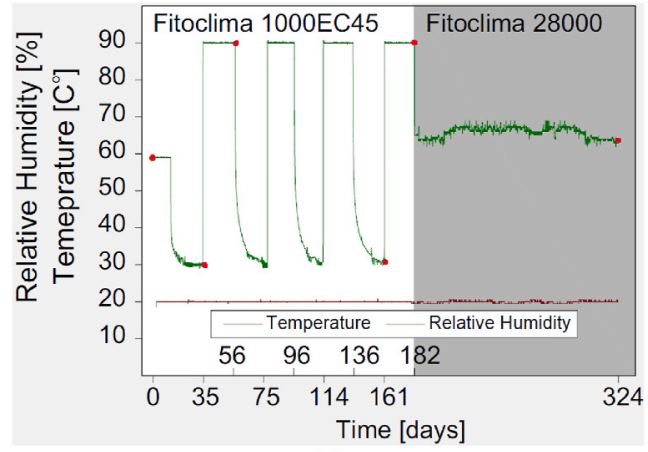

(a)

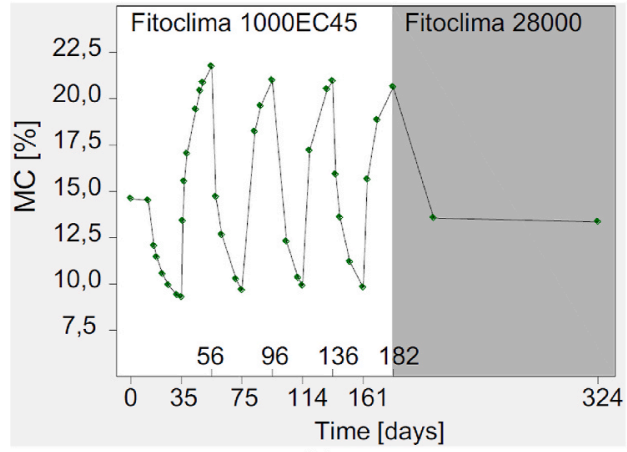

(b)

Fig. 6. (a) Relative humidity and temperature registered by Fitoclima 1000EC45 and Fitoclima 28,000 during 324 days (b) Moisture content registered by control specimens during 324 days.

Table 2

Moisture content during the RH cycles.

\begin{tabular}{llllllllllll}
\hline Day & & 0 & 35 & 56 & 77 & 98 & 119 & 140 & 161 & 182 \\
\hline MC [\%] & MAX. & 14.80 & 9.5 & 22.3 & 9.8 & 21.5 & 10.1 & 21.5 & 10.5 & 21.2 & 13.7 \\
& MEAN & 14.5 & 9.3 & 21.7 & 9.7 & 21 & 9.9 & 20.9 & 9.8 & 20.6 & 13.5 \\
& MIN. & 13.9 & 9 & 20.8 & 9.5 & 20.2 & 9.6 & 20.2 & 9.4 & 20.1 & 13.2 \\
CoV & & 0.018 & 0.015 & 0.019 & 0.011 & 0.018 & 0.017 & 0.017 & 0.03 & 0.016 & 0.015 \\
\hline
\end{tabular}

$\varepsilon_{r e l}=\left(L_{2}-L_{1}\right) / L_{1}$

where $L_{0}$, is the length at day $0, L_{1}$ stands for the current length of remaining test days to the unchanged specimen and $L_{2}$ is the length of remaining test days after cutting specimens into slices (units: $\mathrm{mm}$ ).

The DIC maps measured compressive/tensile restrained strains developed over the specimen surfaces at all three directions of CLT panels: $\mathrm{X}$ - longitudinal in outer layers (OL) and tangential in inner layers (IL); $\mathrm{Y}$ - tangential in outer layers and longitudinal in inner layers; $\mathrm{Z}$ - radial. Immediately afterward, specimens were sliced into 7 pieces (of which just 5 were inside the defined ROI) and imaged again only in their main face (F1) to measure compressive/tensile released strains (see Fig. 5). This procedure allowed evaluating the role of cross-wise lamination over the cross-section of CLT panels. The specimens were sliced through Y direction, in which higher deformations were expected. So, two different DIC maps were done at each test day per each configuration before and after cut, respectively.

Once image acquisition was finished, all timber pieces were measured and weighed, before and after oven-dried, in order to obtain density and moisture content levels for all tested specimens at six different moments. Therefore, it was possible to evaluate density distribution and the moisture content variation as the $\mathrm{RH}$ varies.

The DIC procedure provides the measurement of the displacement field from the speckled pattern images. The strain fields can then be reconstructed from the displacement field using a measure for the straindisplacement relationship and a suitable numerical algorithm. Typically, this implies to compute the partial numerical derivatives of the displacement fields with regard to both $\mathrm{x}$ and $\mathrm{y}$ coordinates. A piecewise polynomial fitting approach is applied, and derivatives are computed from the approximated analytical polynomials. This algorithm yields directly what was called $\mathrm{Y}, \mathrm{Z}$, and shear strain components.

\subsection{Climatic chamber}

CLT specimens were conditioned in climatic chambers for a period of 324 days and submitted to a humidity cycle that varied between $30 \%$ and $90 \%$, for periods of around 21 days, while temperature remained constant $\left(20^{\circ} \mathrm{C}\right)$. This humidity cycle varied in order to keep moisture content levels between $8 \%$ and $18 \%$, respectively. This way, the changes respect the limits imposed by Eurocode 5 regarding service classes 1 and 2 , once according to CLT producers, these are the service classes in which CLT can be applied [19]. Moreover, the long duration (21 days) of each drying/wetting period can also be a cause for the observed behaviour of CLT. Large drying/wetting periods allow a uniform distribution of moisture content through the CLT cross-section, and consequently, fewer moisture gradients are generated. The $\mathrm{RH}$ cycle ends with a period in which the RH remains constant at $65 \%$ for a period of 142 days to ensure standard condition and stabilization.

Fig. 6 (a) depicts relative humidity and temperature registered during $\mathrm{RH}$ cycles and shows that for periods with $\mathrm{RH}=90 \%$ defined environment, was easy/fast to reach. So it can be concluded, that the $\mathrm{RH}$ remains constant during wetting periods. Differently, drying periods present difficulties to reach the defined environment $(\mathrm{RH}=30 \%)$, which keeps constant for less than half of the entire drying period. This is related to the slow release of moisture from timber to the environment. The red dots shown in Fig. 6 (a) mark the moments of testing, which were selected in order to understand the differences between compressive and tensile stresses obtained at the beginning and at the end of $\mathrm{RH}$ cycle.

A set of ten samples with the same dimensions as the test specimens were placed in the climatic chamber during the entire conditioning period in order to control moisture content changes on CLT elements. The results obtained are presented in Fig. 6 (b) and Table 2, showing that the percentage of moisture content responds to the drying and wetting cycles; however, it does not reach the equilibrium for any of the cycles. For drying cycles, moisture content presents values between $9.0 \%$ and $10.5 \%$, while for wetting cycles; moisture content is between $20.1 \%$ and $22.3 \%$.

\section{Experimental results}

Displacements, strain distribution, moisture content and density were measured at six different moments: before initiating RH cycles (day 0 ); at the end of first and last drying and wetting cycles (days 35, 56, 161 and 182); and at the end of final stabilization period (day 324).

In a first observation of the results, an important phenomenon was noticed regarding different moisture flow conditions. Analyzing the variation of moisture content levels for different test moments, it is 
Table 3

Moisture content registered at each test day.

\begin{tabular}{|c|c|c|c|c|c|c|c|c|}
\hline \multicolumn{9}{|c|}{ Moisture Content [\%] (Mean and CoV) } \\
\hline \multirow{2}{*}{$\frac{\text { Test }}{\text { Day }}$} & \multicolumn{4}{|c|}{ Outer Layers } & \multicolumn{4}{|c|}{ Inner Layers } \\
\hline & $\mathrm{C} 1$ & $\mathrm{C} 2$ & C3 & $\mathrm{C} 4$ & $\mathrm{C} 1$ & $\mathrm{C} 2$ & $\mathrm{C} 3$ & $\mathrm{C} 4$ \\
\hline \multirow[t]{2}{*}{35} & 10.7 & 12.5 & 10.3 & 11.7 & 11.1 & 13.2 & 10.2 & 13.5 \\
\hline & 0.04 & 0.02 & 0.04 & 0.02 & 0.04 & 0.03 & 0.02 & 0.01 \\
\hline \multirow[t]{2}{*}{56} & 19.3 & 17.4 & 18.8 & 18.8 & 18.8 & 17.7 & 19.1 & 17.8 \\
\hline & 0.02 & 0.05 & 0.04 & 0.04 & 0.04 & 0.02 & 0.03 & 0.02 \\
\hline \multirow[t]{2}{*}{161} & 10.5 & 13.6 & 10 & 12.5 & 11.5 & 14.6 & 10.8 & 15 \\
\hline & 0.07 & 0.02 & 0.05 & 0.02 & 0.05 & 0.02 & 0.04 & 0.01 \\
\hline \multirow[t]{2}{*}{182} & 19 & 17.9 & 17.5 & 19.5 & 17.7 & 18 & 18 & 18.4 \\
\hline & 0.02 & 0.04 & 0.02 & 0.02 & 0.03 & 0.03 & 0.02 & 0.03 \\
\hline \multirow[t]{2}{*}{324} & 12.8 & 13.3 & 12.9 & 13.3 & 13.4 & 13.9 & 13.2 & 13.9 \\
\hline & 0.01 & 0.02 & 0.02 & 0.01 & 0.02 & 0.01 & 0.01 & 0.01 \\
\hline
\end{tabular}

Table 4

Descriptive statistics of corrected density ( $\rho 12)$.

\begin{tabular}{|c|c|c|c|c|c|c|c|c|}
\hline & \multicolumn{8}{|c|}{ Corrected Density $\left[\mathrm{kg} / \mathrm{m}^{3}\right]$} \\
\hline & \multicolumn{4}{|c|}{ Outer Layers } & \multicolumn{4}{|c|}{ Inner Layers } \\
\hline & C1 & $\mathrm{C} 2$ & C3 & $\mathrm{C} 4$ & $\mathrm{C} 1$ & $\mathrm{C} 2$ & C3 & $\mathrm{C} 4$ \\
\hline Samples & 120 & 100 & 100 & 100 & 60 & 50 & 50 & 50 \\
\hline Max. & 580 & 623 & 636 & 582 & 531 & 757 & 513 & 536 \\
\hline Mean & 452 & 465 & 464 & 458 & 438 & 447 & 444 & 459 \\
\hline Min. & 350 & 372 & 369 & 364 & 352 & 346 & 353 & 327 \\
\hline $\mathrm{CoV}$ & 0.11 & 0.11 & 0.12 & 0.08 & 0.11 & 0.15 & 0.10 & 0.10 \\
\hline 5 th percentile & 358 & 388 & 375 & 391 & 360 & 355 & 361 & 383 \\
\hline
\end{tabular}

possible to understand that, for configurations in which longitudinal direction is sealed (C2 and C4); the range of MC variation is shorter. This behaviour is a consequence of slower water absorption and desorption. Table 3 presents the mean values and $\mathrm{CoV}$ of moisture content registered for outer and inner layers for all four test configurations and for all test days. Slower water absorption/desorption was registered for inner layers of $\mathrm{C} 2$ and $\mathrm{C} 4$, in which MC increases/decreases in a range of $13.8-18 \%$ and $13.5-18.4 \%$, respectively. In contrast, $\mathrm{C} 1$ and $\mathrm{C} 3$ present higher moisture content variations, presenting increases/decreases in a range of $11.1-18.8 \%$ and $10.2-19.1 \%$, respectively. Considering outer layers, differences registered were not so substantial; however, water absorption/desorption remains slower for C2 and C4 in which moisture content increases/decreases in a range of $12.5-17.9 \%$ and $11.7-19.5 \%$, respectively. The remaining configurations present increases/decreases of moisture content in a range of $10.5-19.3 \%$ and $10-18.8 \%$, respectively. Obtained $\mathrm{CoV}$ values are low for all test configurations (0.01-0.07).

It should be noted that the MC at the beginning and the end of the cycle (day 0 and 324 ) was $12 \%$, and this MC was supposed to be a reference MC. In this regard, the density of CLT panels in different configurations whose moisture is equal to $12 \%$ is called "corrected density". Table 4 presents descriptive statistics of obtained values showing that corrected density $(\rho 12)$ varies in a range of $350-636 \mathrm{~kg} / \mathrm{m}^{3}$ and $327-757 \mathrm{~kg} / \mathrm{m}^{3}$ for outer and inner layers. Despite the wide ranges, considering the variability of natural wood and that density was not controlled at production time, the obtained $\mathrm{CoV}$ values are considered low (0.08-0.15). Mean values obtained for outer and inner layers vary in a tighter range of $438-465 \mathrm{~kg} / \mathrm{m}^{3}$.
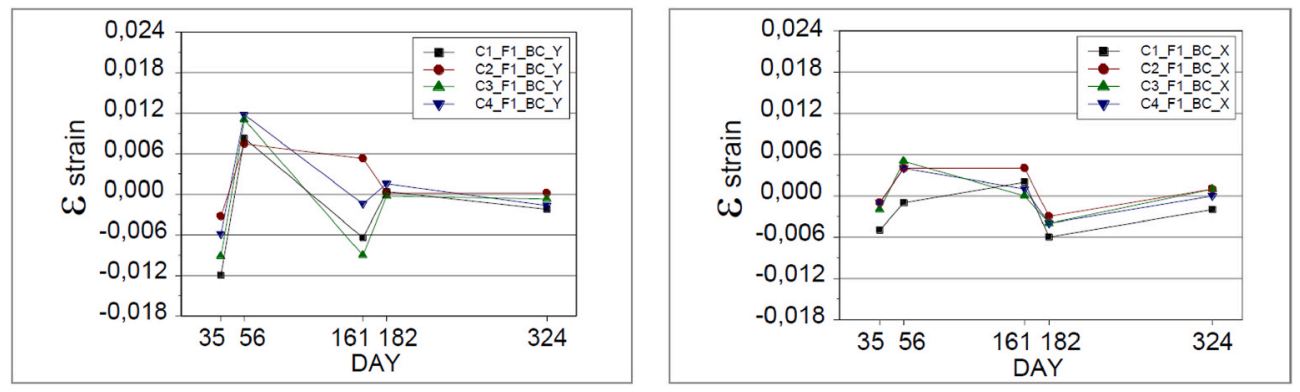

Fig. 7. Mean values of full-field restrained strains distribution measured on F1 specimens.

Table 5

Full-field restrained strains measured on F1 specimens before cut (BC) the specimens.

\begin{tabular}{|c|c|c|c|c|c|c|c|c|c|c|}
\hline \multirow[t]{3}{*}{ Day } & \multicolumn{10}{|c|}{ Restrained Strains $\left(\varepsilon_{\text {rest }}\right)\{$ Max., Mean, Min., CoV $\}$ at different days } \\
\hline & 35 & 56 & 161 & 182 & 324 & 35 & 56 & 161 & 182 & 324 \\
\hline & \multicolumn{5}{|c|}{ Y DIRECTION $\left(\varepsilon_{\text {rest_- }} Y\right)$} & \multicolumn{5}{|c|}{ X DIRECTION $\left(\varepsilon_{\text {rest }} X\right)$} \\
\hline \multirow[t]{4}{*}{$\mathrm{C} 1$} & 0.006 & 0.025 & 0.177 & 0.023 & -0.055 & 0.003 & 0.007 & 0.026 & 0.003 & 0.087 \\
\hline & -0.012 & 0.008 & -0.006 & 0 & -0.002 & -0.005 & -0.001 & 0.002 & -0.006 & -0.002 \\
\hline & -0.024 & -0.041 & -0.028 & -0.013 & 0.016 & -0.013 & -0.007 & -0.049 & -0.013 & -0.02 \\
\hline & -0.28 & 0.77 & -3.81 & -0.27 & -1.4 & -0.37 & -1 & 1.46 & -0.3 & 1.69 \\
\hline \multirow[t]{4}{*}{$\mathrm{C} 2$} & 0.028 & 0.026 & 0.034 & 0.043 & 0.013 & 0.014 & 0.021 & 0.03 & 0.011 & 0.02 \\
\hline & -0.003 & 0.007 & 0.004 & 0 & 0 & -0.001 & 0.004 & 0.005 & -0.003 & 0.001 \\
\hline & -0.026 & -0.005 & -0.01 & -0.02 & -0.012 & -0.023 & -0.009 & -0.066 & -0.024 & -0.018 \\
\hline & -1.06 & 0.48 & 1.17 & 28.67 & 13.36 & -2.9 & 0.56 & 1.15 & -1.25 & 3.64 \\
\hline \multirow[t]{4}{*}{ C3 } & 0.008 & 0.079 & 0.047 & 0.04 & 0.049 & 0.019 & 0.022 & 0.015 & 0.018 & 0.025 \\
\hline & -0.009 & 0.011 & -0.009 & 0 & -0.001 & -0.002 & 0.005 & 0 & -0.004 & 0.001 \\
\hline & -0.034 & -0.125 & -0.028 & -0.042 & -0.02 & -0.079 & -0.024 & -0.014 & -0.025 & -0.029 \\
\hline & -0.36 & 0.6 & -0.53 & -0.22 & -13.79 & -1.29 & 0.47 & -26.18 & -0.82 & 10.41 \\
\hline \multirow[t]{4}{*}{$\mathrm{C} 4$} & 0.022 & 0.026 & 0.01 & 0.014 & 0.068 & 0.005 & 0.011 & 0.016 & 0.004 & 0.011 \\
\hline & -0.006 & 0.012 & -0.001 & 0.002 & -0.002 & -0.001 & 0.004 & 0.001 & -0.004 & 0 \\
\hline & -0.021 & -0.013 & -0.015 & -0.016 & -0.023 & -0.016 & -0.003 & -0.012 & -0.009 & -0.011 \\
\hline & -0.64 & 0.45 & -3.3 & 3.44 & -6.52 & -0.95 & 0.2 & 1.31 & -0.48 & 10.07 \\
\hline
\end{tabular}


Table 6

Ratio between restrained strains obtained for $\mathrm{Y}$ and $\mathrm{X}$ directions during the first DIC mapping.

\begin{tabular}{|c|c|c|c|c|c|}
\hline \multirow[t]{2}{*}{ Ratio } & \multirow{2}{*}{$\overline{\text { Day }}$} & \multicolumn{4}{|c|}{ Configurations } \\
\hline & & $\mathrm{C} 1$ & $\mathrm{C} 2$ & C3 & $\mathrm{C} 4$ \\
\hline \multirow{2}{*}{$\Delta_{F 1}=$} & 35 & 2.5 & 3.2 & 4.9 & 4.2 \\
\hline & 56 & -6.6 & 2.1 & 2.3 & 3.1 \\
\hline$Y_{\text {mean }}$ & 161 & -4.2 & 1 & -59.8 & -1.1 \\
\hline \multirow[t]{2}{*}{$\overline{X_{\text {mean }}}$} & 182 & -0.1 & -0.1 & 0.1 & -0.4 \\
\hline & 324 & 2 & 1.2 & -1.3 & -8.3 \\
\hline
\end{tabular}

\subsection{Digital Image Correlation (DIC)}

\subsubsection{F1 (CLT panels with dimensions of $170 \times 170 \times 93 \mathrm{~mm}$ )}

The DIC maps performed for specimens resulted in full-field restrained strains measured on F1, for $\mathrm{Y}$ and $\mathrm{X}$ directions (see Fig. 7). Moisture content and corrected density registered for both inner and outer layers which were measured from 20 samples used for the second
DIC map, considering 4 configurations at 5 test days, are presented in Tables 3 and 4, respectively.

Table 5 and Fig. 7 present descriptive statistics and graphs of obtained results. Mean values were obtained considering the data of the entire ROI (around $75 \times 75$ subsets). Regarding the first RH cycle, it is evident that tangential direction $(\mathrm{Y})$ presents restrained strains that are significantly higher than those observed for longitudinal direction (X), from -0.012 to 0.012 and from -0.006 to 0.006 , respectively. However, observing the differences between first and last $\mathrm{RH}$ cycles, $\mathrm{Y}$ and $\mathrm{X}$ directions present different trends. While for the $\mathrm{Y}$ direction, it is possible to relate easily compressive and tensile strains associated with drying and wetting cycles, the $\mathrm{X}$ direction does not verify the same trend. Contrary to what was expected, restrained strains measured for the last drying and wetting periods present opposite trends: tensile strains for the drying period and compressive strains for wetting periods.

Analyzing the results obtained for Y direction, it was observed that the influence of different moisture flow conditions on restrained strains is similar (though not so obvious) to that observed for moisture content variations. Again, $\mathrm{C} 1$ allows free moisture flow through all three timber

Table 7

Restrained strains map for specimens $\mathrm{F} 1$ before cut (BC) the specimens in the $\mathrm{X}$ and $\mathrm{Y}$ directions.

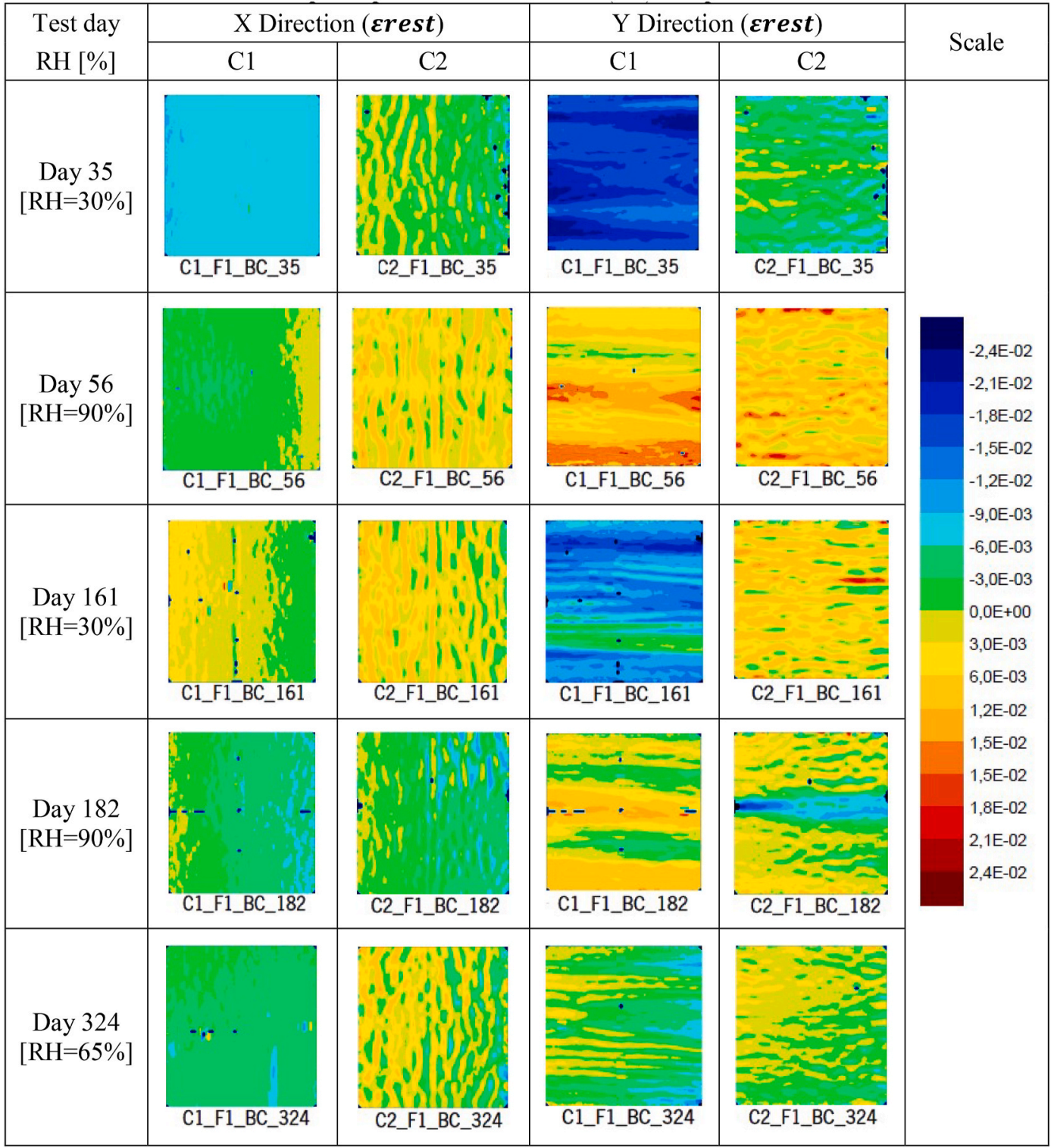


Table 8

Full-field released strains measured after cut the specimens.

\begin{tabular}{lllllll}
\hline & \multicolumn{5}{l}{ Released Strains (Erel) } & Max., Mean, Min., CoV\} at different days \\
\cline { 2 - 7 } & 0 & 35 & 56 & 161 & 182 & 324 \\
\hline C1 & 0.006 & 0.003 & 0.024 & 0.01 & 0.003 & 0.003 \\
& 0 & 0 & 0.02 & 0 & 0 & 0.001 \\
& -0.004 & -0.002 & 0.016 & -0.004 & -0.004 & -0.001 \\
& 1.82 & -0.9 & 0.04 & -4.23 & 0.59 & 0.26 \\
C2 & & 0.027 & 0.022 & 0.004 & 0.003 & 0.003 \\
& & 0.001 & 0.019 & 0 & 0 & 0.002 \\
& & -0.028 & 0.017 & -0.003 & -0.006 & -0.003 \\
& & 1.28 & 0.03 & 0.16 & -0.08 & 0.25 \\
C3 & 0.008 & 0.025 & 0.04 & 0.004 & 0.02 \\
& & 0 & 0.019 & 0.001 & 0 & 0.002 \\
& & -0.005 & 0.014 & -0.005 & -0.003 & 0 \\
& & -6.28 & 0.04 & 1.22 & -0.91 & 0.54 \\
C4 & 0.003 & 0.024 & 0.003 & 0.002 & 0.003 \\
& & 0 & 0.019 & 0 & -0.001 & 0.002 \\
& & -0.002 & 0.015 & -0.002 & -0.004 & 0 \\
& & -3.88 & 0.06 & 0.87 & -0.22 & 0.26 \\
\hline
\end{tabular}
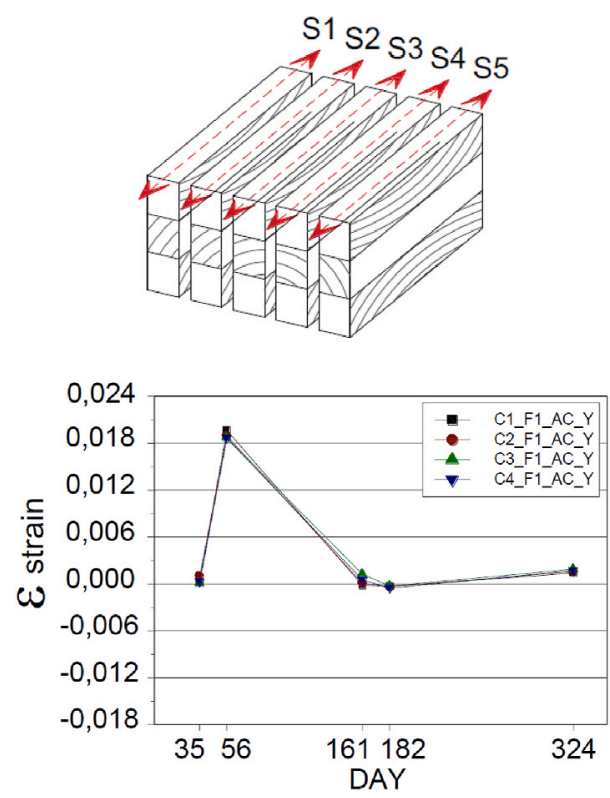

Fig. 8. Mean values of released strains measured on the central longitudinal section of all slices (S1-S5) of specimens.

directions, C2 only in the tangential direction, C3 only in the longitudinal direction and $\mathrm{C} 4$ only in the radial direction. Taking $\mathrm{C} 1$ as a reference, C2 and C4 present a tendency for lower restrained strains: restrained compressive strains are $75 \%$ and $50 \%$ lower for the first drying period and $167 \%$ and $84 \%$ lower for the last drying period, respectively. Because of that, a lower range of strain variation between absorption and desorption periods is also registered. However, differently from what was observed for moisture content variation, restrained strains tend to reduce significantly from first to last drying cycles (Table 5 and Fig. 7). It was observed that configurations that block moisture flow on longitudinal direction present higher restrained strain decreases between the first and last drying periods. Taking day 35 as a reference, from the first to the last drying period, restrained compressive strains reduce $50 \%$ and $0 \%$ for configurations $\mathrm{C} 1$ and $\mathrm{C} 3$, and $-234 \%$ and $84 \%$ for configurations C2 and C4, respectively. Differently, taking day 56 as a reference, losses observed between the first and the last wetting periods present a more homogeneous behaviour: restrained tensile strains reduce $100 \%$ for configurations C1, C2 and C3 and $84 \%$ for configuration $\mathrm{C} 4$. These values agree with the fact that the absorption/ desorption process is significantly slower when the longitudinal direction is sealed, especially if combined with sealing of radial direction (C2). In fact, due to its moisture flow conditions, C2 presents behaviour that is more in line with what was observed for X-direction, inverting the expected strain tendency at the last wetting/drying periods. Finally, in order to quantify the total effect of RH cycles on CLT specimens, and assuming that restrained strains at day 0 are absent, measurements taken at the end of stabilization process (day 324) indicate a slight tendency for compressive strains on the tangential direction (0.00 to -0.002 ).

Regarding $\mathrm{X}$ direction, different moisture flow conditions present some effects during the first drying and wetting periods but in a different way. Taking $\mathrm{C} 1$ as a reference, registered compressive strains for the first drying period are $80 \%, 60 \%$ and $80 \%$ lower for remaining configurations (C2, C3 and C4, respectively). At the end of the first wetting period, C1 does not reach tensile strains, presenting compressive strains of around 0.001 , while the remaining configurations present tensile strains around 0.004 . During the last drying and wetting periods, the differences registered between test configurations are not so substantial. However, it is important to mention that restrained strains do not tend to decrease substantially as the number of cycles increase, as verified for the $\mathrm{Y}$ direction. Finally, observing mean values obtained for day 324 , the causing effects of successive $\mathrm{RH}$ cycles provide restrained strains close to zero with a slight tendency for tensile strains, with the exception of C1 that present compressive strains of -0.001 . This can mean that restraining moisture flow on CLT panel causes observed tensile strains; however, the obtained values are too small to allow a firm conclusion.

In order to analyze the relations between tangential $(\mathrm{Y})$ and longitudinal (X) directions on the main face of CLT panels, the ratio between restrained strains obtained for $\mathrm{Y}$ and $\mathrm{X}$ directions $\left(\Delta_{\mathrm{F} 1}\right)$ was analyzed (Table 6). Observing the results, it is possible to conclude that the ratio between tangential and longitudinal directions tend to be lower at the last $\mathrm{RH}$ cycle. As a consequence of low strains measured in the Y direction at the end of the last wetting period, the lowest differences between the $\mathrm{Y}$ and $\mathrm{X}$-direction are verified at the same moment, varying between -0.4 and 0.1 .

Some values are negative, meaning that strains measured at different directions present opposite signs. In other words, at the same moment when $\mathrm{Y}$ direction present compressive strains, $\mathrm{X}$-direction present tensile strains. This phenomenon is observed for $\mathrm{C} 1$ from the first wetting period to the last wetting period; however, at the end of stabilization period, it turns positive again, meaning that successive $\mathrm{RH}$ cycles do not cause cumulative strains on CLT. The remaining configurations do not present exactly the same behaviour, for which $\Delta_{\mathrm{F} 1}<0$ on different moments just during the last RH cycle and at the end of stabilization process. Here, it is important to underline that C3 and C4 present the same inverted tendency at the end of stabilization process. So, assuming that the tendency observed for C1 presents the typical behaviour for CLT $\Delta_{\mathrm{F} 1 \_\mathrm{C} 1 \_324}=2.0$, successive $\mathrm{RH}$ cycles change the effects of cross-wise lamination for configurations in which tangential direction is sealed.

Actually, there is no published research studying the effect of cyclic humidity changes on dimensional variations of CLT. Jönsson [18] performed an experimental study with glulam submitted to successive $\mathrm{RH}$ cycles in which $\mathrm{RH}$ varies between $40 \%$ and $80 \%$ for periods of 7 days during 101 days on the total. However, the author did not found any effects of $\mathrm{RH}$ cycles on measured strains. Surprisingly, the present research suggests that restrained strains in tangential direction tend to decrease as cycles are repeated. To explain this phenomenon, more research is required; however, three possible causes can be pointed out:

- Results obtained for tangential direction (outer layers) suggest that there is a tendency for restrained strains to reduce as the number of cycles increase. So, restriction of timber movements caused by crosswise lamination can be more effective after successive RH cycles, probably due to some exhaustion of timber fibers;

- The long duration (21 days) of each drying/wetting period can also be a cause for the observed behaviour of CLT. Large drying/wetting 
Table 9

Full field restrained strain distribution shear observed of $\mathrm{C} 1$ from specimens $\mathrm{F} 2$.

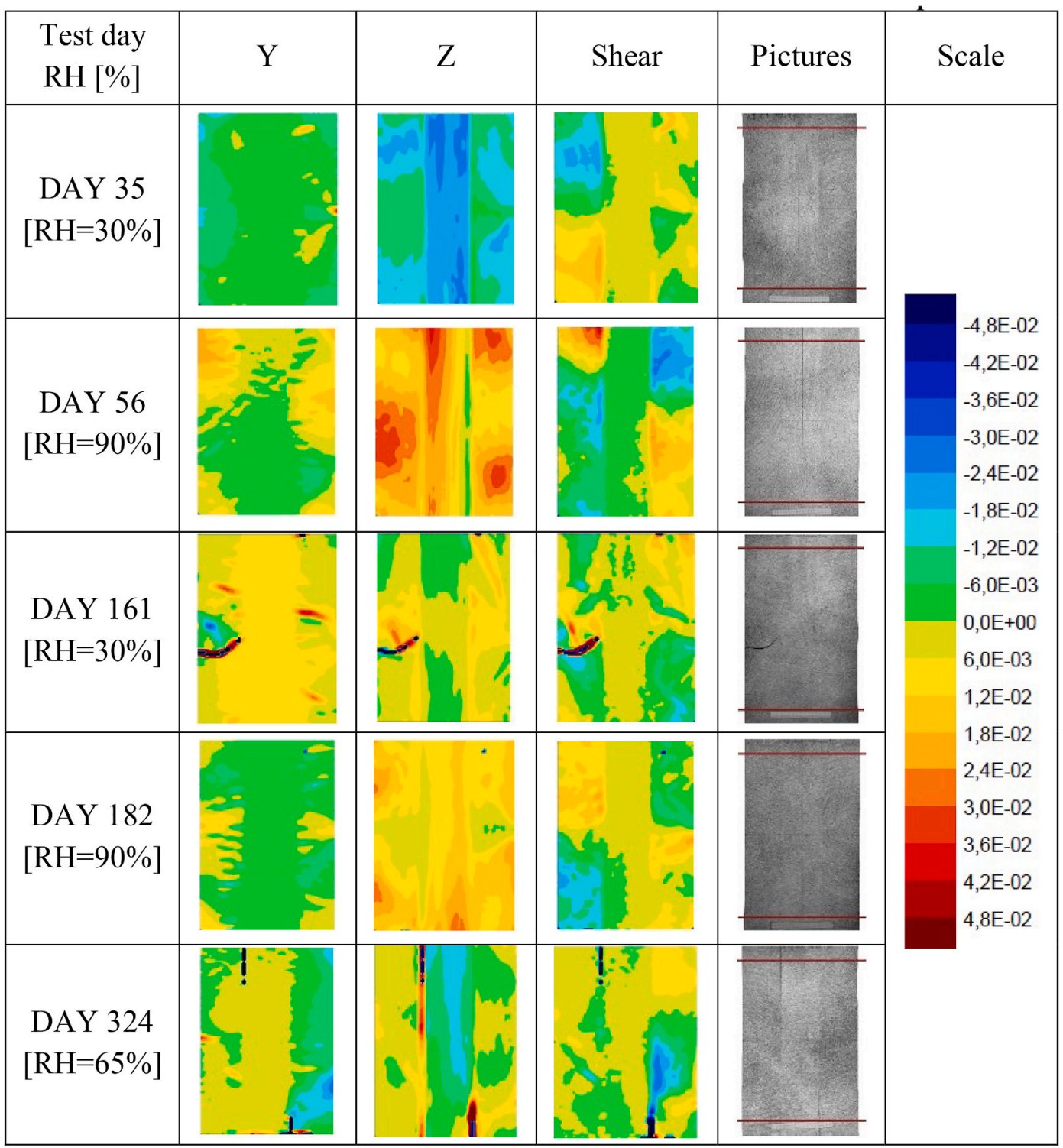

periods allow a uniform distribution of moisture content through the CLT cross-section, and consequently, fewer moisture gradients are generated;

- Successive RH cycles can cause warping/twisting on CLT, which can result in unrealistic strain distribution once the DIC method takes the measurements just on the surface of CLT panels.

Regarding the observed behaviour for longitudinal direction, the explanation should also be related to the same causes: cross-wise lamination, possible fatigue of timber fibers caused by successive RH cycles, and warping/twisting of CLT panels. It is possible that, due to a combination of these three factors, during the last drying and wetting periods, as the middle layers shrink or swell in the tangential direction, outer layers present the opposite tendency in the longitudinal direction.

Graphs depicted in Table 7 show the full field restrained strain distribution on specimens $\mathrm{F} 1$ regarding $\mathrm{X}$ and $\mathrm{Y}$ direction (tangential) for $\mathrm{C} 1$ and C2. Observing color fill graphs, it is possible to identify easily compressive (cold colors) and tensile (warm colors) strains associated with drying and wetting cycles, respectively. It is also possible to observe through Y direction, especially for configurations that were not sealed at the main face of panel ( $\mathrm{C} 1$ and $\mathrm{C} 4)$, that there are differences between strains measured for early and latewood.

Surprisingly, for configurations in which main face is not sealed (C1 and C4), strains distribution is not symmetric, presenting in some cases opposite tendencies between right and left borders. The only explanation found for this tendency is the influence of tangential moisture movements of inner layers which restricts movements of outer layers on longitudinal direction. For configurations C2 and C3 this opposite tendency is not so clear, probably due to some influence of elastic membrane on timber movements.

As previously described, a second DIC mapping was performed. Specimens were sliced in the $\mathrm{Y}$ direction and pictured again in order to take released strains distribution $\left(\varepsilon_{\text {rel }}\right)$. Table 8 presents the mean released strain values taken from all five slices for all four configurations and for all test days, while Fig. 8 depicts the graphs of the same mean values. Mean values were taken from the central longitudinal section of each slice in order to avoid any sawing effects, considering a central area of around $4 \times 74$ facets. Results show that for test days $0,35,161$ and 
Table 10

Full-field restrained strains measured after cut (AC) the specimens.

\begin{tabular}{|c|c|c|c|c|c|c|c|c|c|c|}
\hline & \multicolumn{10}{|c|}{ Restrained Strains (Erest) $\{$ Max., Mean, Min., CoV\} at different days } \\
\hline & \multicolumn{5}{|c|}{ INNER LAYERS (IL) } & \multicolumn{5}{|c|}{ OUTER LAYERS (OL) } \\
\hline & 35 & 56 & 161 & 182 & 324 & 35 & 56 & 161 & 182 & 324 \\
\hline \multirow[t]{4}{*}{$\mathrm{C} 1$} & 0 & 0.001 & 0.017 & 0.001 & 0.057 & 0.011 & 0.022 & 0.065 & 0.05 & 0.009 \\
\hline & -0.002 & -0.001 & 0.009 & -0.004 & 0.001 & -0.004 & 0.003 & 0.002 & -0.003 & -0.002 \\
\hline & -0.004 & -0.004 & 0.006 & -0.005 & -0.011 & -0.015 & -0.039 & -0.015 & -0.023 & -0.009 \\
\hline & -0.21 & -0.74 & 0.04 & -0.11 & 1.07 & -0.85 & 3.8 & 6.95 & -0.79 & 1.03 \\
\hline \multirow[t]{4}{*}{ C2 } & 0.003 & 0.005 & 0.011 & 0.007 & 0.015 & 0.018 & 0.03 & 0.026 & 0.029 & 0.012 \\
\hline & -0.002 & -0.002 & 0.009 & -0.004 & 0 & -0.003 & 0 & 0.009 & -0.002 & 0 \\
\hline & -0.01 & -0.008 & 0.006 & -0.025 & -0.019 & -0.014 & -0.013 & -0.003 & -0.02 & -0.01 \\
\hline & -0.28 & -0.44 & 0.04 & -0.25 & 10.66 & -1.12 & -3.81 & 0.69 & -4.54 & 0.87 \\
\hline \multirow[t]{4}{*}{ C3 } & 0.012 & 0.017 & 0.026 & 0.077 & 0.032 & 0.016 & 0.012 & 0.098 & 0.01 & 0.095 \\
\hline & -0.002 & -0.003 & 0.009 & -0.004 & 0.001 & -0.005 & 0.001 & 0.004 & -0.002 & -0.002 \\
\hline & -0.017 & -0.033 & -0.038 & -0.104 & -0.012 & -0.016 & -0.01 & -0.018 & -0.017 & -0.017 \\
\hline & -0.59 & -1.58 & 0.45 & -1.71 & 4.44 & -0.9 & 1.23 & 2.95 & -2.75 & 3.68 \\
\hline \multirow[t]{4}{*}{ C4 } & 0.007 & 0.006 & 0.025 & 0.003 & 0.013 & 0.005 & 0.013 & 0.026 & 0.014 & 0.021 \\
\hline & -0.002 & -0.003 & 0.009 & -0.004 & 0.001 & -0.004 & 0.001 & 0.008 & -0.001 & 0 \\
\hline & -0.01 & -0.015 & -0.003 & -0.013 & -0.009 & -0.014 & -0.016 & 0 & -0.012 & -0.01 \\
\hline & -0.91 & -0.46 & 0.21 & -0.21 & 2.42 & -0.7 & 1.85 & 0.38 & 8.06 & -14.82 \\
\hline
\end{tabular}
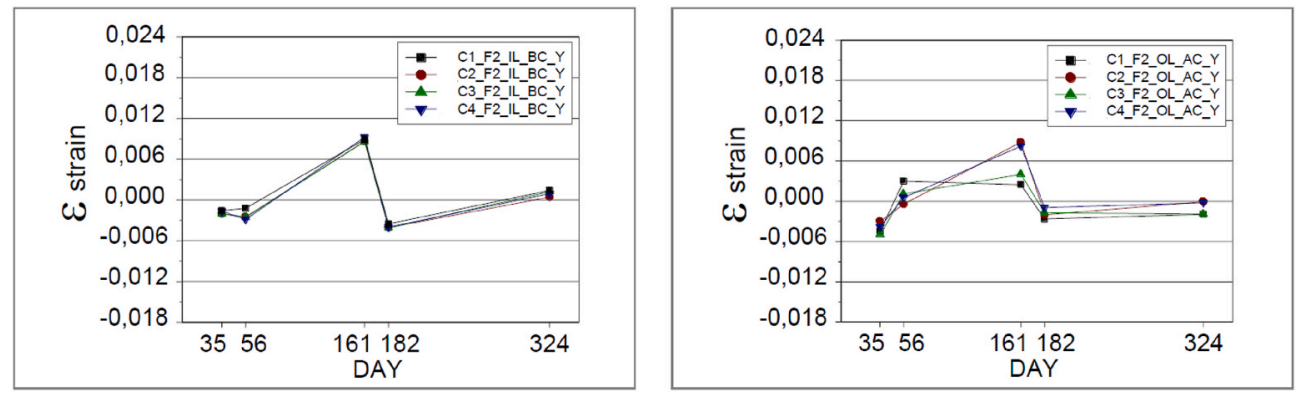

Fig. 9. Full-field restrained strains distribution during first DIC mapping.

Table 11

Full-field restrained strains measured on specimens F2 before cut (BC) the specimens.

\begin{tabular}{|c|c|c|c|c|c|c|c|c|c|c|}
\hline & \multicolumn{10}{|c|}{ Restrained Strains (Erest) $\{$ Max., Mean, Min., CoV\} at different days } \\
\hline & \multicolumn{5}{|c|}{ INNER LAYERS (IL) } & \multicolumn{5}{|c|}{ OUTER LAYERS (OL) } \\
\hline & 35 & 56 & 161 & 182 & 324 & 35 & 56 & 161 & 182 & 324 \\
\hline \multirow[t]{4}{*}{$\mathrm{C} 1$} & -0.016 & 0.023 & -0.003 & 0.02 & 0.006 & -0.004 & 0.018 & 0.031 & 0.019 & 0.008 \\
\hline & -0.024 & 0.014 & -0.008 & 0.009 & -0.006 & -0.012 & 0.006 & 0.008 & 0.007 & -0.001 \\
\hline & -0.033 & 0.006 & -0.015 & 0.002 & -0.014 & -0.023 & -0.007 & -0.009 & -0.002 & -0.007 \\
\hline & -0.15 & 0.24 & -2.15 & 0.43 & -1.01 & -0.31 & -0.52 & 0.84 & 1.28 & -0.14 \\
\hline \multirow[t]{4}{*}{$\mathrm{C} 2$} & -0.006 & 0.035 & 0.008 & 0.03 & 0.003 & 0.005 & 0.034 & 0.035 & 0.036 & 0.01 \\
\hline & -0.016 & 0.019 & 0.001 & 0.017 & -0.006 & -0.007 & 0.008 & 0.011 & 0.008 & 0.001 \\
\hline & -0.023 & 0.001 & -0.004 & -0.01 & -0.014 & -0.015 & -0.01 & -0.007 & -0.012 & -0.007 \\
\hline & -0.14 & 0.35 & 2.17 & 0.29 & -0.57 & -0.48 & 1.13 & 0.62 & 1.28 & -4.38 \\
\hline \multirow[t]{4}{*}{ C3 } & -0.016 & 0.087 & -0.003 & 0.077 & 0.003 & -0.002 & 0.031 & 0.035 & 0.027 & 0.033 \\
\hline & -0.026 & 0.023 & -0.018 & 0.011 & -0.013 & -0.016 & 0.017 & -0.005 & 0.012 & 0 \\
\hline & -0.038 & -0.112 & -0.038 & -0.105 & -0.026 & -0.027 & 0.004 & -0.02 & 0.001 & -0.017 \\
\hline & -0.14 & 0.75 & -0.3 & 1.42 & -0.39 & -0.33 & 0.38 & -1.69 & 0.48 & 0.84 \\
\hline \multirow[t]{4}{*}{ C4 } & -0.004 & 0.026 & 0.019 & 0.031 & 0.003 & -0.002 & 0.027 & 0.016 & 0.035 & 0.023 \\
\hline & -0.01 & 0.016 & 0.012 & 0.02 & -0.004 & -0.01 & 0.012 & 0.006 & 0.016 & 0 \\
\hline & -0.015 & 0.004 & 0.003 & 0.007 & -0.009 & -0.023 & 0 & -0.007 & 0 & -0.007 \\
\hline & -0.18 & 0.24 & 0.17 & 0.22 & -0.45 & -0.38 & 0.44 & 0.82 & 0.49 & 0.02 \\
\hline
\end{tabular}

324 , released strains are close to zero, and tensile strains are predominant independent of the test day/moisture content. So, contrary to what was observed for restrained strains, a clear relation between drying/ wetting periods and compressive/tensile strains was not observed. The effect of high moisture level at production of CLT panels seems not to induce significant released strains, once $\varepsilon_{\text {rel_mean_0_C1_Y }}=0.000$. Obtained released strains present significantly higher values for first wetting period (day 56), which means tensile strains are around 0.019 for all four tested configurations. This phenomenon shows that the effect of cross-wise lamination is more evident during the first wetting period: despite the restrained tensile strains observed during the first DIC mapping, after sliced, timber still tends to swell substantially. Despite being low, compressive strains were registered just at the end of the second wetting period (day 182), which presents the opposite tendency of that observed for day 56. So, similarly to what was observed for restrained strains, there is a clear effect of successive $\mathrm{RH}$ cycles on the hygroscopic behaviour of CLT panels. 

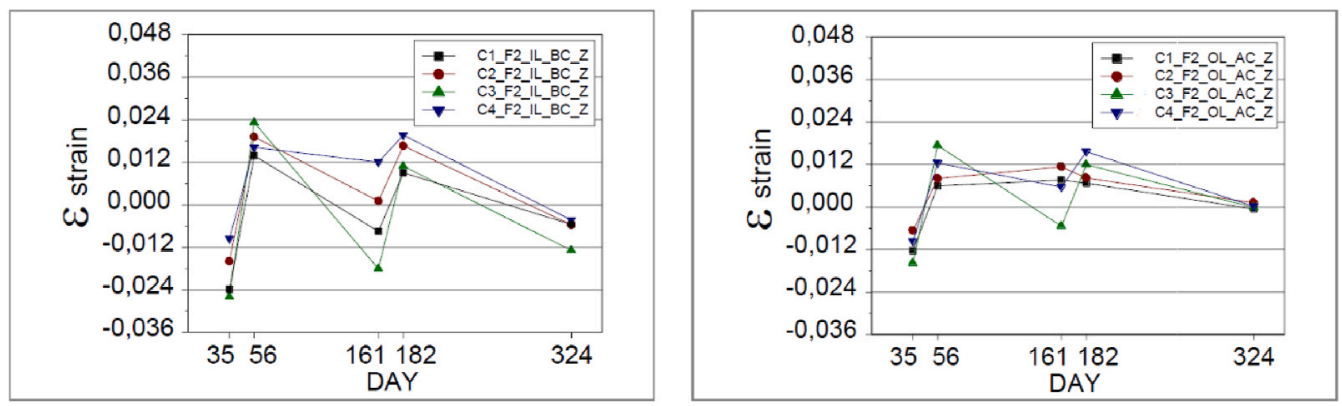

Fig. 10. Full-field restrained strain distribution during first DIC mapping.

Table 12

Full-field restrained strains measured on specimens F3 in X direction.

\begin{tabular}{|c|c|c|c|c|c|c|c|c|c|c|}
\hline & \multicolumn{10}{|c|}{ Restrained Strains (Erest) \{Max., Mean, Min., CoV\} at different days } \\
\hline & \multicolumn{5}{|c|}{ INNER LAYERS (IL) } & \multicolumn{5}{|c|}{ OUTER LAYERS (OL) } \\
\hline & 35 & 56 & 161 & 182 & 324 & 35 & 56 & 161 & 182 & 324 \\
\hline \multirow[t]{4}{*}{$\mathrm{C} 1$} & 0.026 & 0.016 & 0.167 & 0.056 & 0.179 & 0.002 & 0.005 & 0.011 & -0.001 & 0.015 \\
\hline & -0.002 & 0.001 & 0.006 & -0.002 & -0.002 & -0.002 & -0.001 & 0.009 & -0.003 & 0.001 \\
\hline & -0.011 & -0.084 & -0.018 & -0.009 & -0.032 & -0.006 & -0.006 & 0.005 & -0.007 & -0.002 \\
\hline & -0.81 & 9.74 & 2.31 & -2.49 & -9.33 & -0.31 & -1.59 & 0.05 & -0.12 & -3.39 \\
\hline \multirow[t]{4}{*}{ C2 } & 0.015 & 0.059 & 0.025 & 0.018 & 0.015 & 0.002 & 0.002 & 0.01 & 0.003 & 0.006 \\
\hline & -0.002 & -0.001 & 0.009 & -0.003 & 0 & -0.002 & -0.002 & 0.009 & -0.004 & 0.001 \\
\hline & -0.009 & -0.082 & -0.001 & -0.044 & -0.011 & -0.006 & -0.008 & 0.004 & -0.011 & -0.003 \\
\hline & -0.91 & -3.62 & 0.31 & -2.06 & 56.92 & -0.21 & -0.47 & 0.06 & -0.2 & -1.95 \\
\hline \multirow[t]{4}{*}{ C3 } & 0.212 & 0.012 & 0.307 & 0.027 & 0.207 & 0.005 & 0.015 & 0.025 & 0.012 & 0.019 \\
\hline & -0.004 & -0.001 & 0.002 & -0.003 & -0.003 & -0.002 & -0.002 & 0.008 & -0.004 & 0.001 \\
\hline & -0.028 & -0.016 & -0.033 & -0.014 & -0.028 & -0.011 & -0.014 & -0.002 & -0.014 & -0.011 \\
\hline & -7.83 & -2.96 & -10.83 & -1.95 & -12.43 & -0.78 & -1.55 & 0.47 & -0.91 & 12.29 \\
\hline \multirow[t]{4}{*}{$\mathrm{C} 4$} & 0.043 & 0.012 & 0.042 & 0.018 & 0.079 & 0.004 & 0.003 & 0.014 & 0.005 & 0.005 \\
\hline & -0.002 & -0.002 & 0.009 & -0.003 & 0 & -0.002 & -0.002 & 0.009 & -0.004 & 0.001 \\
\hline & -0.014 & -0.015 & 0.002 & -0.016 & -0.081 & -0.007 & -0.01 & 0.003 & -0.013 & -0.004 \\
\hline & -1.88 & -1.53 & 0.13 & -1.21 & 12.51 & -0.44 & -0.61 & 0.07 & -0.47 & -3.07 \\
\hline
\end{tabular}
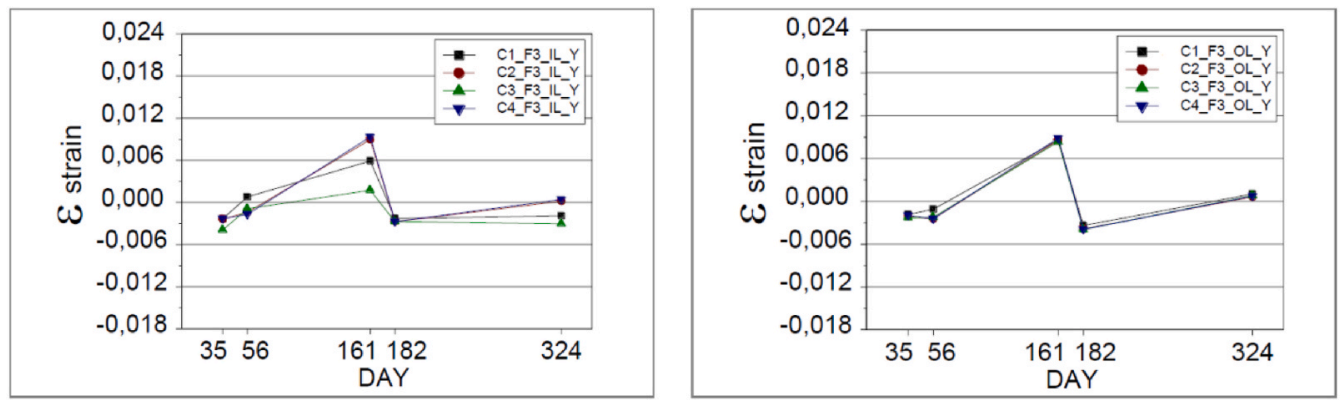

Fig. 11. Full-field restrained strains distribution measured on specimens F3, during first DIC mapping.

3.1.2. F2 and F3 (CLT panels with dimensions of $170 \times 170 \times 93 \mathrm{~mm}^{3}$ )

Herein F2 and F3 (see Fig. 5 for indication of faces) will also be analyzed. F2 is one of the lateral faces of CLT panel in which outer layers are subjected to movements in the tangential direction and inner layer in the longitudinal direction. Specimen F3 presents exactly the opposite arrangement. Regarding F2, Table 10 and Fig. 9 summarize the behaviour of all four configurations for inner and outer layers separately. Inner layers present predominant compressive strains during the first $\mathrm{RH}$ cycle, while during the last RH cycle, they present tensile strains for drying periods and compressive strains for wetting periods. It is important to mention here that for the last $\mathrm{RH}$ cycle, the results obtained for F1 presented the same tendency in the $\mathrm{X}$ direction, which also quantifies the movements in the longitudinal direction. Surprisingly, during the last RH cycle, the outer layers present the opposite tendency of that observed for F1 in the Y direction (tangential). This may be related to restrictions of timber movements caused by cross-wise lamination. In fact, observing full-field strains distribution presented in Table 9 it is possible to notice that outer layers suffer tensile and compressive strains through $\mathrm{Y}$ direction, which are also dependent on growth ring orientation. That is why shear strains present the diagonal symmetry depicted by color fill graphs. In contrast, inner layers present a more homogeneous strain distribution.

Different moisture flow conditions do not affect the results regarding inner layers, and no differences between test configurations were observed. On the contrary, outer layers present some differences at the last drying period (day 161). The last drying period presents the highest tensile strains observed either for inner layers or outer layers. However, while inner layers present the same mean value for all four configurations $\varepsilon_{\text {rest_mean_0_C1./C4_IL_Y }}=0.009$, outer layers present different ranges: for $\mathrm{C} 1$ and $\mathrm{C} 30.002 \leq \cdot \varepsilon_{\text {rest_mean_161_C1. } / C 3{ }_{-} O L_{-} Y} \cdot \leq \cdot 0.004$ and for C2 and C4 $0.008 \leq \cdot \varepsilon_{\text {rest_mean_161_C2./C4_OL_Y }} \cdot \leq \cdot 0.009$. This difference should be directly related to sealing of longitudinal direction, which 
Table 13

Full field restrained strain distribution shear observed of $\mathrm{C} 1$ from specimens F3.

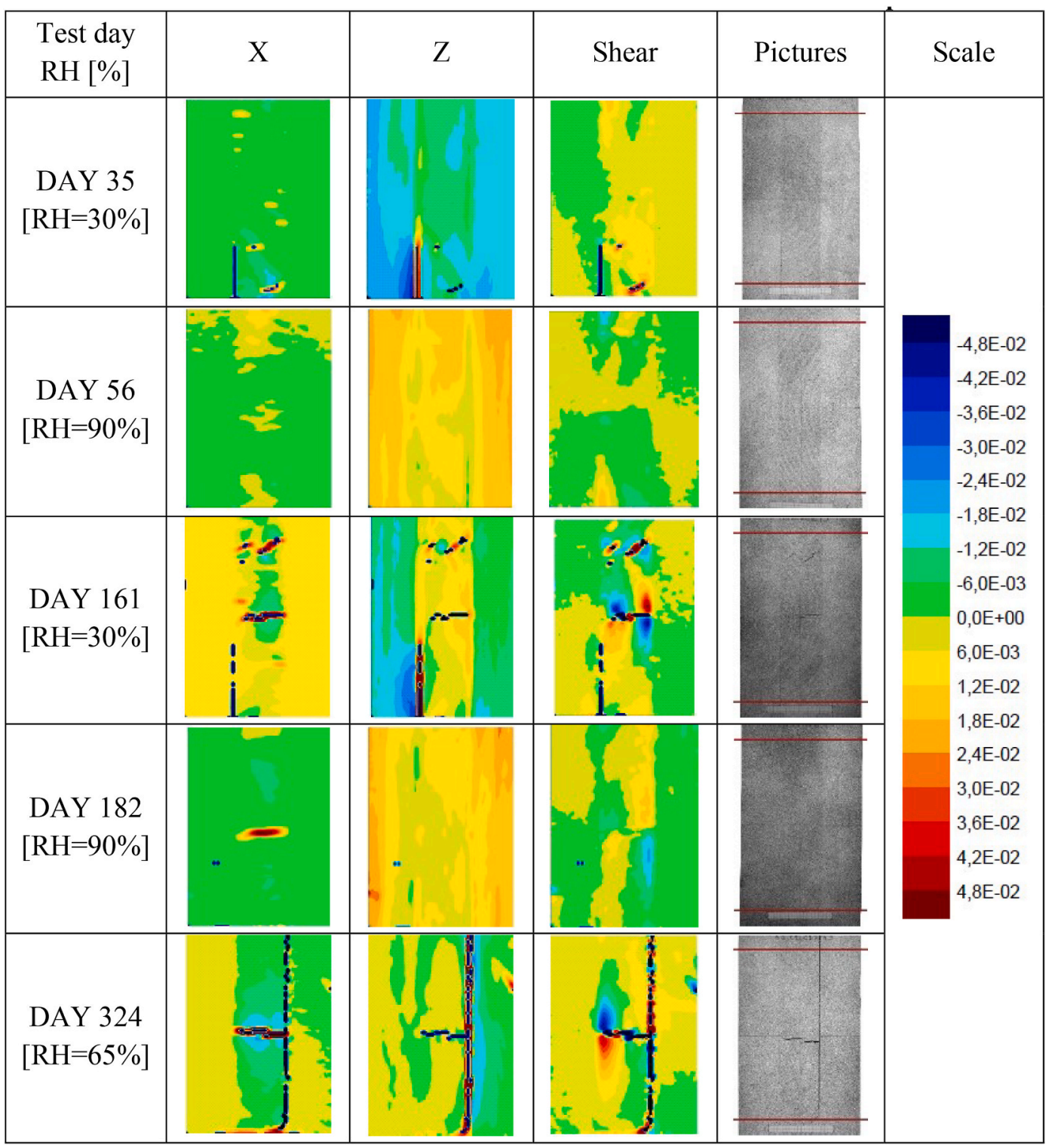

delays the desorption process during the drying period resulting in a lower ratio between tangential and longitudinal directions $(1.0 \leq$. $\left.\varepsilon_{\text {rest_161_C2./C4_OL_Y }} / \varepsilon_{\text {rest__161_C2_C4_Il_Y }} \cdot \leq \cdot 1.1\right)$.

At the end of stabilization period, the same tendency observed for F1 is also verified for measures taken in F2: outer layers (tangential direction) present predominant compressive strains while inner layers (longitudinal direction) present predominant tensile strains. Despite this tendency, obtained mean strains are very close to zero, meaning that successive RH cycles do not cause cumulative strains.

Regarding Z direction, inner layers of F2 answer to $\mathrm{RH}$ cycles as expected, presenting shrinking/swelling movements for drying/wetting periods, respectively (Table 11). The influence of moisture flow conditions are verified again at day 161 , in which the slow desorption process does not let C2 and C4 to reach compressive strains. Independent of moisture flow conditions, the radial direction of inner layers seems to be affected by successive $\mathrm{RH}$ cycles, especially regarding drying periods. It also can be observed in Fig. 10 that the last drying period present lower compressive strains for $\mathrm{C} 1$ and C3 while C2 and C4 present tensile strains. Decreases presented by C1 and C3 are $66.6 \%$ and $30.7 \%$, respectively. At the end of stabilization period, inner layers tend to be under compressive strains for all test configurations $(-0.013 . \leq$. $\left.\varepsilon_{\text {rest_mean_324_C1-C4_IL_Z } .} \leq-0.004\right)$.

Unpredictably, and similarly to what was observed for Y direction, outer layers tend to present predominant tensile strains at the last $\mathrm{RH}$ cycle. Outer layers also present tensile and compressive strains depending on growth ring orientation. However, with the exception of $\mathrm{C} 3$, even during drying periods, tensile strains tend to be predominant $\left(0.006 \cdot \leq \cdot \varepsilon_{\text {rest_mean_161_C1/C2/C4_OL_- }} \cdot \leq 0.011\right)$. Configurations that restrict moisture flow in the tangential direction (inner layers) are the only configurations that present shrinking movements between the first wetting and last drying periods for outer layers. This may mean that sealing tangential direction changes the effect of cross-wise lamination as the number of cycles increase.

Regarding wetting periods, the differences obtained between days 56 and 182 are not so substantial. Higher differences were registered for C3, which presents strains $29.4 \%$ lower at day 182 . Successive RH cycles seem to reduce the range between drying and wetting periods, and at the end of stabilization period, strains tend to zero for all test configurations. 
Table 14

Full-field restrained strains measured on specimens F3, during first DIC mapping.

\begin{tabular}{|c|c|c|c|c|c|c|c|c|c|c|}
\hline & \multicolumn{10}{|c|}{ Restrained Strains (Erest) $\{$ Max., Mean, Min., CoV\} at different days } \\
\hline & \multicolumn{5}{|c|}{ INNER LAYERS (IL) } & \multicolumn{5}{|c|}{ OUTER LAYERS (OL) } \\
\hline & 35 & 56 & 161 & 182 & 324 & 35 & 56 & 161 & 182 & 324 \\
\hline \multirow[t]{4}{*}{$\mathrm{C} 1$} & 0.002 & 0.017 & 0.029 & 0.012 & 0.029 & -0.005 & 0.012 & 0 & 0.022 & 0.008 \\
\hline & -0.003 & 0.006 & 0.005 & 0.006 & 0.001 & -0.009 & 0.007 & -0.006 & 0.012 & -0.002 \\
\hline & -0.007 & -0.041 & -0.011 & 0 & -0.016 & -0.015 & 0.001 & -0.018 & 0.004 & -0.011 \\
\hline & -0.31 & 4.11 & 0.76 & 0.43 & 3.68 & -0.23 & -1.06 & -0.87 & 0.32 & 1.59 \\
\hline \multirow[t]{4}{*}{ C2 } & 0.002 & 0.029 & 0.029 & 0.024 & 0.016 & -0.012 & 0.028 & 0.003 & 0.028 & 0 \\
\hline & -0.005 & 0.004 & 0.01 & 0.007 & 0.001 & -0.016 & 0.019 & -0.004 & 0.016 & -0.004 \\
\hline & -0.012 & -0.03 & -0.003 & -0.013 & -0.009 & -0.02 & 0.009 & -0.01 & 0.009 & -0.009 \\
\hline & -0.38 & 4.22 & 0.28 & 0.98 & 2.25 & -0.1 & 0.2 & -0.53 & 0.18 & -0.44 \\
\hline \multirow[t]{4}{*}{ C3 } & 0.058 & 0.025 & 0.026 & 0.023 & 0.029 & -0.012 & 0.043 & 0 & 0.034 & 0.009 \\
\hline & -0.009 & 0.015 & 0 & 0.01 & 0 & -0.016 & 0.014 & -0.01 & 0.01 & -0.004 \\
\hline & -0.019 & 0.002 & -0.02 & -0.005 & -0.062 & -0.021 & -0.008 & -0.018 & -0.015 & -0.015 \\
\hline & -0.81 & 0.24 & -0.32 & 0.36 & 1.93 & -0.11 & 0.71 & -0.25 & 1.08 & 0.21 \\
\hline \multirow[t]{4}{*}{ C4 } & 0.002 & 0.014 & 0.017 & 0.03 & 0.008 & -0.003 & 0.023 & 0.015 & 0.033 & 0.005 \\
\hline & -0.003 & 0.005 & 0.013 & 0.007 & 0.002 & -0.009 & 0.013 & 0.007 & 0.018 & 0 \\
\hline & -0.007 & -0.006 & 0.008 & -0.009 & -0.004 & -0.015 & 0.005 & -0.002 & 0.001 & -0.005 \\
\hline & -0.41 & 0.74 & 0.07 & 0.69 & 0.47 & -0.28 & 0.25 & 0.54 & 0.28 & 0.43 \\
\hline
\end{tabular}
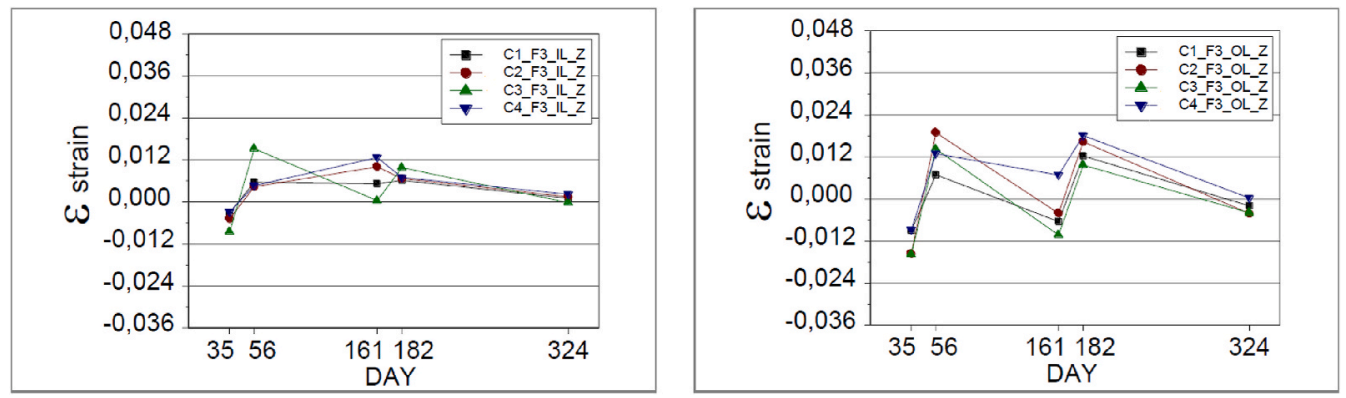

Fig. 12. Mean values of full-field restrained strains distribution measured on specimens F3, during first DIC mapping.

Strains measured in F3 are summarized in Table 12 and Fig. 11 for all four configurations considering inner and outer layers separately. As expected, the differences observed between inner and outer layers are not so relevant in this CLT lateral face once the layer that presents tangential movements (inner layer) is restricted by layers that shrink/ swell in the longitudinal direction (outer layers). Observing full field strains distribution, regarding $\mathrm{X}$ direction, presented in Table 13 restriction is very obvious once the obtained patterns are much more homogeneous than those obtained for F2_Y. This way, graphs depicted in Fig. 11 are more in line with that of inner layers from F2, presenting high tensile strains during the last drying period, shrinking tendency in the previous wetting period and swelling tendency during stabilization period (see Table 14).

Despite the small differences observed for outer layers of F2, mean restrained strains measured in $\mathrm{F} 2$ and $\mathrm{F} 3$, for $\mathrm{Y}$ and $\mathrm{X}$ directions, either inner or outer layers varies within the same range $(-0.005 \leq$. $\varepsilon_{\text {rest_mean_ } Y / X^{*}} \leq 0.009$ ). Evaluating results obtained for F3 in the $\mathrm{Z}$ direction, the tendency is inverted when comparing with results obtained for F2. Movements in the radial direction are not restrained by crosswise lamination so; the range of compressive/tensile strains is just dependent on grain orientation. This way ranges obtained for F2 (outer layers) and F3 (inner layers) are very close to each other: $-0.016 . \leq$. $\varepsilon_{\text {rest_mean_F2_OL_Z }} \leq 0.017$ and $-0.009 \cdot \leq \varepsilon_{\text {rest_mean_F3_IL_Z }} \cdot \leq 0.015$. Ranges obtained for F2 (inner layers) and F3 (outer layers) are slightly higher for F2: $-0.026 \cdot \leq \varepsilon_{\text {rest_mean_F2_IL_Z }} \leq 0.023$ and $-0.016 \cdot \leq$. $\varepsilon_{\text {rest_mean_F3_OL_Z }} \leq 0.018$. However, the behaviour through the RH cycles is similar (Fig. 12 and Table 13).

\section{Conclusions}

A comprehensive experimental analysis was performed on CLT panels under consecutive RH changes by means of DIC technique to measure restrained and released strains, as well as dimensional stability. CLT panels were divided into four separated specimen with regard to the direction in which moisture freely flow.

The analysis of restrained strains, resulted from the cyclic moisture in the different directions of both the main and lateral face of the CLT specimen, allowed to draw the following conclusions:

- When evaluating restrained strains in the longitudinal direction, measurements performed in the main face of CLT panels (F1 - X direction) suggest that successive $\mathrm{RH}$ cycles tend to invert the normal tendency of wood movements when submitted to drying/wetting environments. In other words, drying periods present tensile strains, while wetting periods present compressive strains. One possible explanation for this phenomenon is the accumulation of strains during several cycles;

- Otherwise, when evaluating restrained strains in the tangential direction (F1 - Y direction), measurements performed in the main face of CLT panels suggest that, differently from what was observed for moisture content variation, restrained strains tend to reduce significantly from first to last drying cycles for all test configurations;

- However, when restrained strains in the tangential direction are measured in the lateral face of CLT panels (F2 - outer layers), the drying period presents tensile strains while the wetting period presents compressive strains. This fact may be related to restrictions caused by cross-wise lamination and growth ring orientation; 
- Regarding different moisture flow conditions, configurations that restrict moisture flow on longitudinal direction (C2 and C4) present slower water desorption and because of that suggest a tendency for lower restrained strains measured through $\mathrm{Y}$ direction of the main face of CLT panels (F1), during drying periods;

- Measurements taken on specimens F1 suggest that the ratio between tangential and longitudinal directions tend to decrease with the number of RH cycles;

- Assuming that the ratio between tangential and longitudinal directions $(\mathrm{T} / \mathrm{L}$ ) at the end of stabilization period (day 324) for configuration $\mathrm{C} 1$ is $2.0\left(\Delta_{F 1}\right.$ C1_324 $\left._{3} \cdot=2.0\right)$, it can be concluded that successive RH cycles change the effects of cross-wise lamination for configurations in which tangential direction is sealed (C3 and C4): $\Delta_{F 1 \_C 3 \_324^{\circ}}=-1.3$ and $\Delta_{F 1 \_C 4 \_324}=-8.3$;

- CLT tends to present always reduced strain values at the end of stabilization period, meaning that successive RH cycles do not cause cumulative strains on CLT. However, tangential direction presents a slight tendency for compressive strains while longitudinal direction presents a slight tendency for tensile strains;

- Regarding measurements taken in the $\mathrm{Z}$ direction, it can be concluded that the radial direction movements are not restrained by cross-wise lamination being just dependent on timber grain orientation.

In the other hand, and regarding the released strains measured in the main face (F1) of the CLT panels, additional discussion can be pointed out:

- Tensile strains are predominant independent of the test day/moisture content;

- No effect of different moisture flow conditions was observed;

- It is during the first wetting period that effects of cross-wise laminations are more evident: despite the restrained tensile strains observed during first DIC mapping after sliced timber still tends to swell substantially;

- Released strains tend to reduce as the number of cycles increase;

- Compressive restrained strains observed at the first DIC map became tensile released strains at the second DIC map, proofing the existence of restriction of timber movements caused by cross-wise lamination.

As a future study, a separate experimental analysis, considering effect of cyclic moisture on induced-stresses of CLT panels, should be carried out to approve the presented results and assumptions. In this regard, a parallel numerical analysis is highly recommended.

\section{Author statement}

Catarina Silva: investigation, methodology, writing - original draft. Jorge Branco: conceptualization, methodology, validation, resource. Zabih Mehdipour: visualization, writing - review \& editing. José Xavier: Methodology, Software. Arthur S. Rebouças: visualization, writing review \& editing. Paulo B. Lourenço: writing - review \& editing, supervision.

\section{Declaration of competing interest}

The authors declare that they have no known competing financial interests or personal relationships that could have appeared to influence the work reported in this paper.

\section{Acknowledgement}

The financial support of the Portuguese Science Foundation (Fundação de Ciência e Tecnologia, FCT), through PhD grant SFRH/BD/ $79972 / 2011$ is gratefully acknowledged.

\section{References}

[1] E.L. Schmidt, M. Riggio, A.R. Barbosa, I. Mugabo, Environmental response of a CLT floor panel: lessons for moisture management and monitoring of mass timber buildings, Build. Environ. 148 (2019) 609-622, https://doi.org/10.1016/j. buildenv.2018.11.038. Jan.

[2] J. Tripathi, R.W. Rice, Finite element modelling of heat and moisture transfer through cross laminated timber panels, BioResources 14 (3) (2019) 6278-6293, https://doi.org/10.15376/biores.14.3.6278-6293. Aug.

[3] E. Schwab, A. Steffen, C. Korte, In-plane swelling and shrinkage of wood-based panels, Holz Als Roh-Und Werkst 55 (4) (1997) 227-233.

[4] R. Brandner, Production and technology of cross laminated timber (CLT): a stateof-the-art report, in: Focus Solid Timber Solut. - Eur. Conf. Cross Laminated Timber, 2014, pp. 3-36. May 2013.

[5] C. Bengtsson, Variation of moisture induced movements in Norway spruce (Picea abies), Ann. For. Sci. 58 (5) (2001) 569-581, https://doi.org/10.1051/forest: 2001146.

[6] V. Kukk, A. Külaots, J. Kers, T. Kalamees, Influence of interior layer properties to moisture dry-out of CLT walls, Can. J. Civ. Eng. 46 (11) (2019) 1001-1009, https://doi.org/10.1139/cjce-2018-0591.

[7] E. Schmidt, M. Riggio, Monitoring moisture performance of cross-laminated timber building elements during construction, Buildings 9 (6) (2019), https://doi.org/ 10.3390/BUILDINGS9060144.

[8] C.H. P Hoffmeyer, Wood as a building material, TIMBER Eng. step 1 (A4) (1995).

[9] A. Gülzow, K. Richter, R. Steiger, Influence of wood moisture content on bending and shear stiffness of cross laminated timber panels, Eur. J. Wood Wood Prod. 69 (2) (2011) 193-197, https://doi.org/10.1007/s00107-010-0416-z. May.

[10] J.A. Nairn, Predicting layer cracks in cross-laminated timber with evaluations of strategies for suppressing them, Eur. J. Wood Wood Prod. (2019), https://doi.org/ 10.1007/s00107-019-01399-7.

[11] T. Gereke, T. Schnider, A. Hurst, P. Niemz, Identification of moisture-induced stresses in cross-laminated wood panels from beech wood (Fagus sylvatica L.), Wood Sci. Technol. 43 (3-4) (2009) 301-315, https://doi.org/10.1007/s00226008-0218-1. May.

[12] M.M. Hassani, F.K. Wittel, S. Ammann, P. Niemz, H.J. Herrmann, Moisture-induced damage evolution in laminated beech, Wood Sci. Technol. 50 (5) (2016) 917-940, https://doi.org/10.1007/s00226-016-0821-5. Sep.

[13] Y.L. Dong, B. Pan, A review of speckle pattern fabrication and assessment for digital image correlation, Exp. Mech. 57 (8) (2017), https://doi.org/10.1007/ s11340-017-0283-1.

[14] J.L. Pereira, J. Xavier, B. Ghiassi, J. Lousada, J. Morais, On the identification of earlywood and latewood radial elastic modulus of Pinus pinaster by digital image correlation: a parametric analysis, J. Strain Anal. Eng. Des. 53 (8) (2018), https:// doi.org/10.1177/0309324718786351.

[15] H. Schreier, J.J. Orteu, M.A. Sutton, Image Correlation for Shape, Motion and Deformation Measurements: Basic Concepts, Theory and Applications, 2009.

[16] J. Xavier, A. M. P. de Jesus, J. J. L. Morais, and J. M. T. Pinto, "Stereovision measurements on evaluating the modulus of elasticity of wood by compression tests parallel to the grain," Construct. Build. Mater., vol. 26, no. 1, pp. 207-215, Jan. 2012, doi: 10.1016/j.conbuildmat.2011.06.012.

[17] V. Angst, K.A. Malo, The effect of climate variations on glulam-An experimental study, Eur. J. Wood Wood Prod. 70 (5) (2012) 603-613, https://doi.org/10.1007/ s00107-012-0594-y. Sep.

[18] J. Jönsson, Internal stresses in the cross-grain direction in glulam induced by climate variations, Holzforschung 58 (2) (2004) 154-159, https://doi.org/ 10.1515/HF.2004.023.

[19] Klh-Massivholzplatten, ETA-06/0138, OIB/EOTA, " Vienna, 2011. 